NATIONAL LABORATORY

\title{
Magnetic Processing of Steel Strip and Next Generation Alloys
}

\section{April 26, 2013}

\author{
Prepared by \\ Dr. Gerard (Gerry) M. Ludtka \\ Distinguished R\&D Staff
}

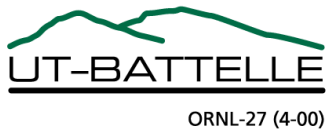




\section{DOCUMENT AVAILABILITY}

Reports produced after January 1, 1996, are generally available free via the U.S. Department of Energy (DOE) Information Bridge.

Web site http://www.osti.gov/bridge

Reports produced before January 1, 1996, may be purchased by members of the public from the following source.

National Technical Information Service
5285 Port Royal Road
Springfield, VA 22161
Telephone 703-605-6000 (1-800-553-6847)
TDD 703-487-4639
Fax 703-605-6900
E-mail info@ntis.gov
Web site http://www.ntis.gov/support/ordernowabout.htm

Reports are available to DOE employees, DOE contractors, Energy Technology Data Exchange (ETDE) representatives, and International Nuclear Information System (INIS) representatives from the following source.

Office of Scientific and Technical Information

P.O. Box 62

Oak Ridge, TN 37831

Telephone 865-576-8401

Fax 865-576-5728

E-mail reports@osti.gov

Web site http://www.osti.gov/contact.html

This report was prepared as an account of work sponsored by an agency of the United States Government. Neither the United States Government nor any agency thereof, nor any of their employees, makes any warranty, express or implied, or assumes any legal liability or responsibility for the accuracy, completeness, or usefulness of any information, apparatus, product, or process disclosed, or represents that its use would not infringe privately owned rights. Reference herein to any specific commercial product, process, or service by trade name, trademark, manufacturer, or otherwise, does not necessarily constitute or imply its endorsement, recommendation, or favoring by the United States Government or any agency thereof. The views and opinions of authors expressed herein do not necessarily state or reflect those of the United States Government or any agency thereof. 
DOE EERE Advanced Manufacturing Office (Formerly Industrial Technologies Program) Advanced Materials R\&D in Support of EERE Needs to Advance Clean Energy Technologies of the American Recovery and Reinvestment Act (ARRA) of 2009

CPS Agreement 20912

August 31, 2009 to November 30, 2012

FINAL TECHNICAL REPORT: MAGNETIC PROCESSING OF STEEL STRIP AND NEXT GENERATION ALLOYS

\author{
Authors \\ Gerard (Gerry) M. Ludtka \\ (865-574-5098, ludtkagm1@ornl.gov) \\ Gail Mackiewicz Ludtka \\ Orlando Rios \\ John B. Wilgen \\ Chad M. Parish \\ Hiram Rogers \\ Roger A. Kisner \\ Don M. Nicholson \\ Tom Watkins, \\ Alexandru Stoica \\ David White (Maryville College) \\ Bart L. Murphy
}

Date Published: April 26, 2013

Prepared by

OAK RIDGE NATIONAL LABORATORY

Oak Ridge, Tennessee 37831-6283

managed by

UT-BATTELLE, LLC

for the

U.S. DEPARTMENT OF ENERGY

under contract DE-AC05-00OR22725 



\section{CONTENTS}

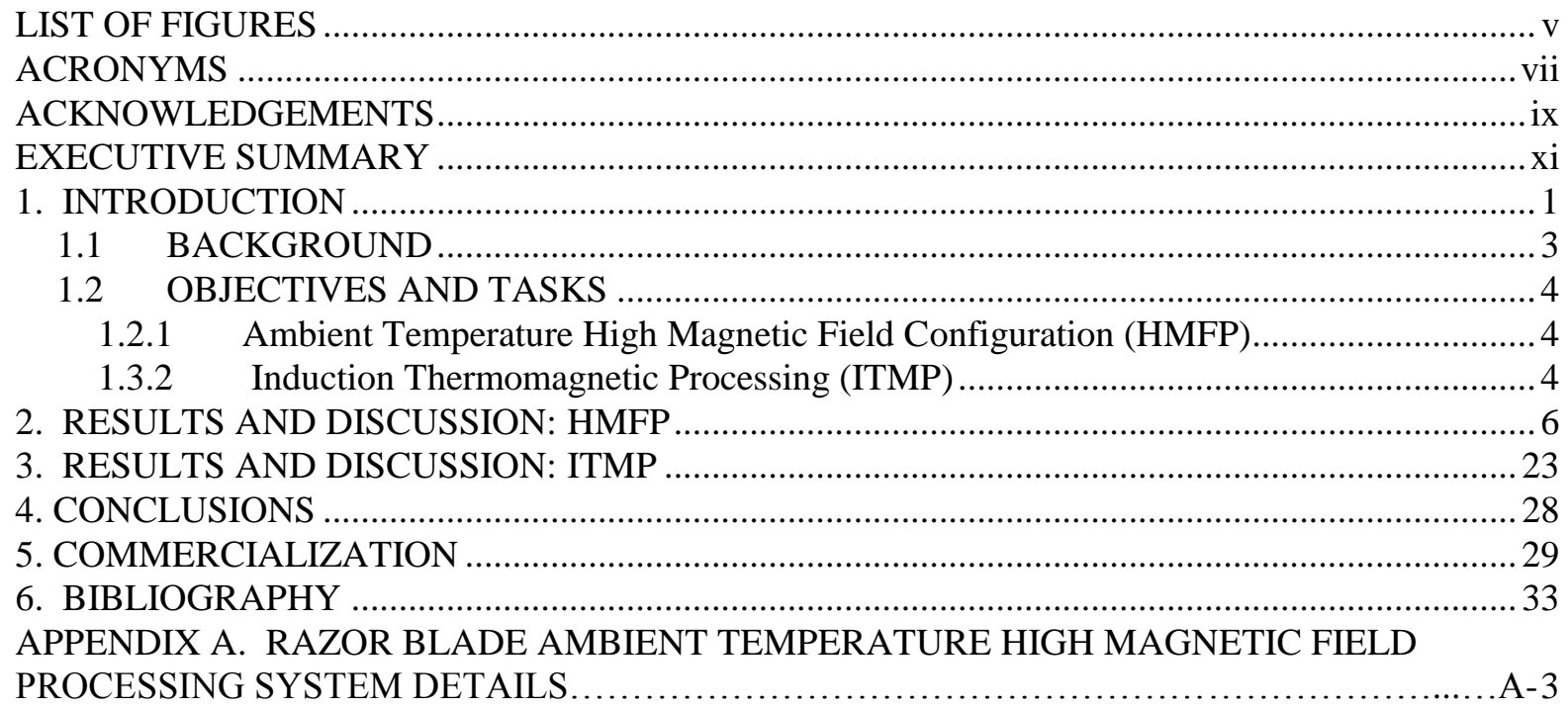





\section{LIST OF FIGURES}

Figure 1. Photos showing the laboratory scale "mocked-set-up" used to simulate the high temperature processing and quench step for the razor blade processing line: (a) shows the razor blade material on the spooler/tensioner entering the furnance, (b) shows the blade as it is exiting the chill blocks and being guided by the pulleys into the entrance of the magnet. (c) shows the blade exiting the furnace

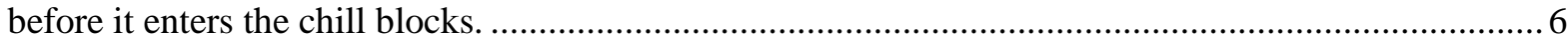

Figure 2. ORNL sample feed system with active line tension and speed control............................... 8 Figure 3. Side View of Optical Probe (with optical fiber connected) ….......................................... 8 Figure 4. Notional mount design for the 4000E probe........................................................................ 10 Figure 5. Structural analysis of a, b, c) austenitized and quenched sample and a magnetically

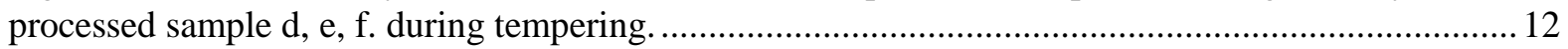

Figure 6. Structural analysis of a cryo-quenched sample during tempering..................................... 13 Figure 7. (a) SEM image of polished sample. Box indicates $30 \times 30 \mu \mathrm{m}$ EBSD scan area. (b) EBSD phase map without using chemical information. (c) Confidence index map without using chemical information.

Figure 8. (a) Image quality map. (b) Fe X-ray map. (c) Cr X-ray map. (d) Automated partitioning of the IQ+Fe+Cr maps into four regions for re-indexing.

Figure 9. (a) Re-indexed phase map using chemical information. (b) Confidence index map using chemical information.

Figure 10. Plot showing the amount of retained austenite after quenching for several austenitization times and water blocks at room temperature (RTWQ) and chilled water (LTWQ). .......................... 17 Figure 11. Plot showing the amount of retained austenite before and after magnetic processing at 9 Tesla for the heat treatment matrix.

Figure 12. Plot showing the Vickers hardness before and after magnetic processing at 9 Tesla for the heat treatment matrix.

Figure 13. Plot showing the relationship between the initial retained austenite before magnetic processing and amount of retained austenite converted by high magnetic field processing.....

Figure 14. Carbides are structurally similar to the ferrite and dissimilar from austenite. The combined EBSD and EDS technique are shown here.

Figure 15. Phase analysis of processed materials which was austenitized, water quenched and cryo-

quenched.

Figure 16. Phase analysis of sample B5 which was austenitized then water quenched. .....................21

Figure 17. Phase analysis of sample D3 which was austenitized, water quenched and passed through a

9 Tesla field.

Figure 18. World's first commercial prototype ITMPsystem with an $\sim 8$-inch diameter, vertical warm bore superconducting magnet system (with recondensing cryocoolers for zero cryogen replacement capability) and $200 \mathrm{KW}$ dual-frequency induction heating system with integral 75 gpm polymer-water quench.

Figure 19. Internal induction heating insert with integral quench capability used for this investigation prior to installation in the vertical bore of the commercial prototype superconducting magnet system.24 Figure 20. Typical ferrous alloy components (left to right: large torsion fatigue sample, orbital drive, small torsion fatigue sample, gear) that would need to be handled by the commercial prototype system at insertion rates up to 10 inches/s while under a 9 tesla magnet field. Figure 21. A typical ferrous alloy test component instrumented for temperature measurement with a Type S intrinsic thermocouple spot-welded to the sample surface. Sample is shown at the top entrance of the superconducting magnet being held by the 2000-pound force sample handling system. Liquid helium recondensing cryocooler components (multiple vertical assemblies) are shown in the background. 
Figure 22. Schematic of a 1-T recondensing magnet design with a 24-inch diameter warm bore that would be viable for continuous processing of ferrous alloy bar and rod industrial applications. Figure 23. Schematic production-rate capable prototype commercial system with all of the system enhancements identified in this project that would have been the first implementation of the H\&TMP technology.

Figure 24. An illustration of the high forces as a function of field strength that may be exerted on a ferromagnetic sample while going through the magnetic field gradient of a superconducting magnet. An 8-inch long torsional fatigue sample would have the apparent mass of the 4 sport motorcycles depicted in this graphic.

Figure 25. Production rate, commercial ITMP systems with continuous feed sample insertion systems can be intelligently designed such that the effective handling force on the samples approaches very low values. 


\section{ACRONYMS}

$\begin{array}{ll}\text { AFA } & \text { Alumina Forming Austenitic } \\ \text { AMI } & \text { American Magnetics, Inc. } \\ \text { AMO } & \text { Advanced Manufacturing Office } \\ \text { ARRA } & \text { American Recovery and Reinvestment Act } \\ \text { ATM } & \text { AjaxTOCCO Magnethermic } \\ \text { B } & \text { Magnetic Field } \\ \text { BCT } & \text { Body-Centered Tetragonal } \\ \text { DARPA } & \text { Defense Advanced Research Projects Agency } \\ \text { DOE } & \text { Department of Energy } \\ \text { EBSD } & \text { Electron Back-Scattered Diffraction } \\ \text { EDS } & \text { Energy Dispersive Spectroscopy } \\ \text { EDX } & \text { Energy-Dispersive X-ray Analysis } \\ \text { EERE } & \text { Energy Efficiency and Renewable Energy } \\ \text { EMAT } & \text { Electro-Magnetic Acoustic Transducer } \\ \text { FCC } & \text { Face Centered Cubic } \\ \text { GPM } & \text { Gallons per Minute } \\ \text { HMFP } & \text { High Magnetic Field Processing } \\ \text { ITMP } & \text { Induction Thermomagnetic Processing } \\ \text { IQ } & \text { Image Quality } \\ \text { Khz } & \text { Kilohertz } \\ \text { KW } & \text { Kilowatt } \\ \text { Mpa } & \text { MegaPascal } \\ \text { ORNL } & \text { Oak Ridge National Laboratory } \\ \text { PLC } & \text { Programmable Logic Controller } \\ \text { RA } & \text { Retained Austenite } \\ \text { R\&D } & \text { Research and Development } \\ \text { SC } & \text { SuperConducting } \\ \text { SNS } & \text { Spallation Neutron Source } \\ \text { T } & \text { Temperature } \\ \text { TCP/IP } & \text { Transmission Control Protocol/Internet Protocol } \\ \text { TMP } & \text { ThermoMagnetic Processing } \\ \text { TTT/CCT } & \text { Time-Temperature-Transformation/Continuous Cooling Transformation } \\ \text { WQ } & \text { Water Quenched } \\ \text { XRD } & \text { X-Ray Diffraction } \\ & \end{array}$




\section{ACKNOWLEDGEMENTS}

This report is based upon work supported by the Advanced Manufacturing Office (AMO) of the U. S. Department of Energy under CPS Agreement 20912 via the Advanced Materials R\&D in Support of EERE Needs to Advance Clean Energy Technologies Program of the American Recovery and Reinvestment Act (ARRA) of 2009. 


\section{EXECUTIVE SUMMARY}

High magnetic field processing was applied in two separate process configurations. In the first configuration, a laboratory-scale continuous razor blade processing line incorporating ORNL's ambient temperature high magnetic field technology for increased energy efficiency and material performance enhancement was successfully demonstrated during the project. This facility simulated a critical portion of a high temperature heat-treatment razor blade material processing line and demonstrated that a costly and energy inefficient cryogenic cooling processing to control retained austenite (RA) could be eliminated with an ambient temperature magnetic process. Magnetic processing resulted in improved process energy efficiency, reduced microstructural variability in the final product, and higher hardness for better performance than currently employed cryogenic commercial processing. Therefore, from both a technical and cost benefit perspective, high magnetic field processing incorporated into a razor strip production line was shown to be a technically-feasible, commercially-viable approach to making a superior blade razor product.

For the razor blade application, a series of refined experimental matrices on the newly commissioned equipment were conducted and analyzed. Besides the very energy-efficient 9 tesla, 5 -inch diameter horizontal bore superconducting magnet component, a custom horizontal clamshell 3-zone tube furnace was incorporated into the system. The three zones were tuned in order to provide a precise laboratory scale thermal profile of a razor blade production line heat treating thermal profile to control essential carbide volume fraction and minimize retained austenite present in the final product for optimal high strength, durability, and reliability. A continuous steel strip feed system was an integral component providing dynamic feedback for speed and line tension control. This unique tensioning system facilitated effective precision simulation of a high speed manufacturing process in a laboratory scale.

The experimental testing involving production-environment-like continuous processing simulations resulted in defining the impact of the two main processing parameters: 1.) the interrelation between the solution treatment time and the resulting microstructures, especially carbide volume fraction, and, 2.) the effect of the production-line chilled quench block temperature at the exit of the furnace assembly on the resulting microstructure with and without magnetic processing. This was accomplished by a series of experiments where in one instance a constant time to quench was maintained while for the second series of experiments, a constant time at the solution temperature was used while varying quench block temperature.

Via extensive $\mathrm{x}$-ray diffraction analysis of the continuously processed materials from these experiments, several very promising outcomes were shown for ambient temperature magnetic field processing. Microstructural analysis revealed that high magnetic field processing produces materials that are microstructurally more consistent resulting in less process variability in the final product which has major positive ramifications from an improved industrial process control perspective. A notable conclusion is that through magnetic processing the amount of retained austenite converted to martensite by high magnetic field processing is linearly dependent of the initial amount of retained austenite. Therefore, if more retained austenite exists in the strip before ambient temperature magnetic processing the more of that undesirable soft phase gets converted to the desirable high-strength martensite phase. This result mitigates some of the structural variations that plague high throughput commercial quench and temper processes. Essentially, in this application, magnetic processing was shown to reduce the variation in materials with microstructures differing by over $5 \% \mathrm{wt} \% \mathrm{RA}$ down to less than one percent. Additionally the interrelation between heat treatment hold time, retained austenite and final hardness in the razor strip product was characterized. Thus the project successfully 
demonstrated that the ambient temperature magnetic field processing heat-treatment approach that does not require cryo-quenching results in a finer, harder, and more homogeneous microstructure than conventional processes today for this razor blade steel strip heat treating application.

A significant development of this project involved making a major analytic methodology inroad to address a prior-unresolved analyses problem for the steel and analytic communities. In order to address some of the limitations and systematic uncertainties associated with phase fraction measurement of textured materials (such as steel strip) through X-ray diffraction, a new electron based analytical technique was developed. This new analyses methodology resolved the issue that overlapping X-ray peaks and strong texture make it difficult to precisely determine RA volume fraction, which is a vital metric to compare processing paths. Additionally X-ray analysis did not provide conclusive information about the morphology of the phases present. Combining energy dispersive spectroscopy and electron back-scattered diffraction analyses methods (EDS+EBSD), a feasible approach was developed to provide quantitatively accurate measurements for the volume fractions of cubic carbides in a matrix of ferrite/martensite and austenite. This technique was applied in this investigation of the materials processed on a razor blade production line and the advanced ambient temperature magnetic processing materials from the ORNL prototype facility.

High magnetic field processing was combined with induction heating in the second configuration to treat typical power system industrial pump and transportation drive train components. This work was targeted at completing system validation of a previously developed commercial scale prototype high magnetic field processing system. This system is the first of its kind and incorporates several novel design concepts ${ }^{1}$ for system durability. The system was shown to be an industrially robust design capable of handling the demands on all of the components to meet the high throughput requirements of an industrial environment. This commercial prototype is comprised of a 2000-pound force extraction/sample handling system involving sample rotation during heating and quenching that is integrated around a 9 tesla, $\sim 8$-inch diameter vertical bore superconducting magnet system with a 200 KW $(10-30 \mathrm{KHz})$ induction heating power supply and an in-bore $75 \mathrm{gpm}$ quenching system. Because of the high forces exerted on the high magnetic field superconducting solenoid coils during ferromagnetic sample insertion into the bore of the prototype system and the possibility of magnet quenching (loss of superconductivity due to temperature rise) due to inherent system component interactions, a series of critical experiments were conducted to prove commercial viability. These tests showed that relatively large commercial components (several pound ferrous alloy samples [e.g., orbital drive or gear] which would have a maximum extraction force up to 2000 pounds exerted on them) can be inserted and extracted rapidly at up to 10 inches per second with multiple cycles (up to 45 were demonstrated) while under a 9 tesla magnetic field without causing any negative power changes in or quenching of the magnet solenoid. Tests under induction heating power were similarly conducted with no negative impact. These experiments provided critical data required by our technology commercialization partners AjaxTOCCO Magnethermic (ATM) and American Magnetics Inc. (AMI) to successfully design future next generation commercial prototype superconducting magnet systems incorporating induction heating systems for industrial applications at production rate speeds. This project has not identified any high magnetic field or magnetic quench related equipment issues for ORNL's commercial prototype system that might limit its application for a broad range of typical ferrous alloy component applications within the existing magnet bore size constraints.

\footnotetext{
${ }^{1}$ Commercial prototype special design features described in "High Magnetic Field Processing -A Heat-Free Heat Treating Method”, Gerard M. Ludtka, ORNL/TM-2012/78, August 8, 2012. Available at: www.osti.gov/servlets/purl/1049805/
} 


\section{INTRODUCTION}

The extreme high magnetic field (B) environment, generally coupled with elevated temperature (T), provides an enabling disruptive technology for making significant major science and technological advances in developing the next generation of novel structural and functional materials for broad energy and military applications. All materials are impacted by high magnetic fields and so all material systems from metallic through polymeric and protein will respond to a BT environment. Major improvements in performance (from $15 \%$ to $300 \%$ ) can be manifested in mechanical and/or physical properties as well as the development of nanocrystalline or textured microstructures or reaction paths made easier/faster through the synthesis/catalytic chemical effect of the extreme BT environment. In addition, the deformation behavior (magnetoplasticity) of materials appears to be impacted by high fields potentially enabling high and low cycle fatigue damage mitigation (life extension), superplastic behavior at ambient temperature, residual stress relief, and other visionary applications. Perhaps classically brittle materials can be made to be formable under high magnetic fields. The BT environment therefore impacts phase equilibria and kinetics, is a new synthesis/catalysis paradigm, and a deformation/life enhancement processing breakthrough technology. This project was focused at two very specific commercialization thrusts related to demonstrating the very beneficial technological and energy efficiency impacts of high magnetic field processing and the robustness of ORNL's commercial prototype system to handle production rate (such as 300 6-pound gears per hour) processing parameters. The latter was essential for the potential high magnetic field equipment commercialization companies to understand the robustness and limitations of their current commercial prototype design concepts.

The initial application target for this technology was a safety razor blade material application. The BT environment facilitates the development of the next generation of enhanced performance structural materials using a state variable that has been largely ignored before and results in: 1) new phase equilibria (no longer 1 phase diagram), 2) enhanced phase transformation kinetics (no longer just 1 Time-Temperature-Transformation/Continuous Cooling Transformation [TTT/CCT] set of responses, 3.) novel microstructures, and 4.) a new synthesis/catalysis path to overcome major reaction path barriers. DOE's Advanced Manufacturing Office previously funded research at ORNL ${ }^{2}$ and open literature publications show a broad range of non-optimized performance improvements that span anywhere from $10 \%$ through $>100 \%$. Steels can exhibit $20 \%$ increases in strength with no loss of ductility in one instance, while in another alloy a $12 \%$ increase in strength is achieved simultaneously with a $22 \%$ increase in impact energy making that alloy superior in toughness to a 250 -grade maraging steel without having to use Co as an alloy addition. Similarly, a 15\% increase in strength is achieved for a precipitation hardening $\mathrm{Mg}$ alloy using thermomagnetic processing (TMP). Preliminary results in an exploratory DARPA project indicated that solution heat-treatment in a magnetic field (9T) achieved $12-59 \%$ creep-rupture life improvement in a selected composition range of carbide strengthened alumina-forming austenitic stainless steels at $750^{\circ} \mathrm{C}$ and $130 \mathrm{MPa}$, yielding in the range of $200-500 \mathrm{~h}$ rupture lifetime.

In this project, magnetic processing equipment and parameters for the High Magnetic Field Processing (HMFP) Technology were developed to demonstrate the response and performance in a continuous processing line for the fabrication of steel strip razor blades based on ORNL's earlier experience ${ }^{2}$ in

2 "Exploring Ultrahigh Magnetic Field Processing of Materials for Developing Customized Microstructures and Enhanced Performance”, Ludtka, G. M., Jaramillo, R. A., Kisner, R. A., Mackiewicz-Ludtka, G., Wilgen, J. B., ORNL Tech. memo, ORNL/TM-2005/79, March 2005. 
using ambient temperature high magnetic fields for converting generally undesirable low strength retained austenite to the desirable high strength martensite microstructure. The effort has the potential to facilitate significant energy savings, cost benefits and carbon reductions. These benefits are viable through: 1) improving materials response and performance properties by using HMFP to tailor the microstructure, kinetics and mechanical performance of selected materials alloy systems; 2) eliminating and/or reducing cryogen usage; and 3) replacing and eliminating current, less energy efficient, thermal processing processes.

The intent of the project was to validate the technology at a meaningful scale for an industrial application. The earliest opportunity to do this was determined to be through validation of the technology's durability in an ITMP application. Therefore the focus of the project moved from a limited one product razor application to the broadly applicable ITMP application. This was accomplished by developing the critical data essential to conceptualizing and defining the specifications for an industrially-robust, production-rate capable commercial system. Achieving this goal would facilitate the development of a cost-effective industrial system satisfying the application needs of potential system purchasers who have shown near-term interest to commercialize this technology.

To satisfy a typical industrial heat treating production requirement, a production-rate capable system specification was made to nominally process 300 6-pound gears per hour. An industrially-robust system requires that the production-rates can be met without any deleterious effects on the ITMP system. All superconducting magnet systems can be sensitive to "magnet quenching" (which means a rapid loss of cryogens). Since these cryogens are necessary to keep the superconducting (SC) coils at full field strength, a magnet quench would result in a complete loss of the magnetic field resulting in significant down time needed to refill and re-energize the superconducting magnet to full field strength. These magnet quenches can be induced by transient magnet field pulses $(\mathrm{dB} / \mathrm{dt}$ where $\mathrm{B}$ is magnetic field strength and $t$ is time) due to movement of a mass in the magnetic field gradient region of the superconducting coil. Rapid insertion of large industrial components into the bore of the magnet may initiate such a quench condition. Similarly, an Electro-Magnetic Acoustic Transducer (EMAT) effect (non-contact acoustic alternating pulses) at lower induction heating power system frequencies (such as 15 to $30 \mathrm{KHz}$ ) combined with an increasing inductor coil power may induce critical vibrations in the magnetic system that cause a momentary increase in temperature locally in the SC coils resulting in a potential magnet quench. To mitigate these EMAT effects and prevent this EMAT-induced type of quench, AMI has incorporated multiple design features in their new magnet designs. However, these new system features had never been tested on a commercial scale system under commercial induction heating and sample insertion rates.

This was a collaborative investigation involving ORNL, ATM, and AMI. Very systematic parametric study experiments were conducted, whereby sample insertion rates ( 0.5 to 10 -inches per sec), magnetic field strengths (from 0 to 9 Tesla), and induction heating power settings ( 0 to $200 \mathrm{KW}$ ) were varied on ORNL's commercial scale prototype system while monitoring SC magnet coil voltage parameters for any indication of a transient signal spike that might lead to a magnet quench. The study first involved only the sample handling system and induction insert with no industrial part in place, and then, repeated with a ferrous alloy component (such as an orbital drive) held in the induction insert for actual processing. This information was crucial design criteria data needed for the technology commercializers, ATM and AMI, to design industrially-robust, production-rate capable, commercial system specifications for future end-user Gausstempering ${ }^{\text {TM,3 }}$ (ITMP) applications.

3 Gausstemper $^{\mathrm{TM}}$ is an ORNL trademark for the process of magnetically processing any material in a magnetic field. 


\subsection{BACKGROUND}

For decades, commercial steel and heat-treating operations have been plagued with costly conventional processing steps (e.g., cryogenic treatments, long double-temper cycles) needed to reduce the amount of retained austenite (RA) developed during standard steel processing. However, without these additional process steps, component life and product performance would be severely compromised and result in premature failures. Research at ORNL has demonstrated that high magnet field processing reduces residual stresses and destabilizes and reduces retained austenite, eliminating these energy intensive and costly specialized industrial thermal processing steps. An application focused on processing strip steel used in the manufacture of razor blades was chosen as an opportunity to demonstrate commercialization of this technology. The results of this R\&D effort were anticipated to lead to significant energy savings, cost benefits and carbon reductions for future industrial implementation applications through: 1) improving materials response and performance properties by using HMFP to tailor the microstructure, kinetics and mechanical performance of selected materials alloy systems; 2) eliminating and/or reducing cryogen usage; and 3) replacing and eliminating current, less energy efficient, thermal processing processes. An industrial scale system was replicated and demonstrated in the laboratory.

After completion of HMFP testing, it was determined that the earliest opportunity to validate the technology at meaningful scale would be through validation of the technology's durability in an ITMP application. This would be accomplished by developing the critical data essential to conceptualizing and defining the specifications for an industrially-robust, production-rate capable commercial system. Achieving this goal would facilitate the development of a cost-effective industrial system satisfying the application needs of potential system purchasers who have shown interest to commercialize this technology. To satisfy a typical industrial heat treating production requirement, a production-rate capable system specification was made to nominally process 3006 -pound gears per hour. An industrially-robust system requires that the production-rates can be met without any deleterious effects on the ITMP system.

All superconducting magnet systems can be sensitive to "magnet quenching" (which means a rapid loss of cryogens). Since these cryogens are necessary to keep the superconducting (SC) coils at full field strength, a magnet quench would result in a complete loss of the magnetic field resulting in significant down time needed to refill and re-energize the SC magnet to full field strength. These magnet quenches can be induced by transient magnet field pulses $(\mathrm{dB} / \mathrm{dt}$ where $\mathrm{B}$ is magnetic field strength and $t$ is time) due to movement of a mass in the magnetic field gradient region of the SC coil. Rapid insertion of large industrial components into the bore of the magnet may initiate such a quench condition. Similarly, the EMAT effect (non-contact acoustic alternating pulses) at lower induction heating power system frequencies (such as 15 to $30 \mathrm{KHz}$ ) combined with an increasing inductor coil power may induce critical vibrations in the magnetic system that cause a momentary increase in temperature locally in the SC coils resulting in a potential magnet quench. To mitigate these EMAT effects and prevent this EMAT-induced type of quench, AMI has incorporated multiple design features in their new magnet designs. However, these new system features have never been tested on a commercial scale system under commercial induction heating and sample insertion rates.

This project involved a collaborative investigation involving ORNL, ATM, and AMI. Very systematic parametric study experiments were conducted, whereby sample insertion rates $(0.5$ to 10 inches per sec), magnetic field strengths (from 0 to 9 Tesla), and induction heating power settings ( 0 to $200 \mathrm{KW}$ ) were varied on ORNL's commercial prototype system while monitoring SC magnet coil voltage parameters for any indication of a transient signal spike that might lead to a magnet quench. This study first involved only the sample handling system and induction insert with no industrial part 
in place, and then, repeated with a ferrous alloy component (such as an orbital drive) held in the induction insert for actual processing. This information would provide the crucial design criteria data needed for the future technology commercializers, ATM and AMI, to define and guarantee industrially-robust, production-rate capable, commercial system specifications for future technology end-user customers' applications.

\subsection{OBJECTIVES AND TASKS}

This section defines those tasks covering two configurations of high magnetic field processing (HMFP), development of an ambient temperature high magnetic field configuration for a razor blade application and a validation of an induction thermomagnetic process (ITMP) to replace energy inefficient heat treating applications.

\subsubsection{Ambient Temperature High Magnetic Field Process (HMFP) Configuration}

The goal of this effort was, for the first time, to engineer a magnet processing system focused on continuous operation of long metallic continuous strips. The focus of this effort was to develop the applicability of high magnetic field processing (HMFP) technology for a prototype continuous commercial application. The project would develop, design and demonstrate high magnetic field processing in an industrial continuous razor blade strip application to facilitate more widespread commercial implementation of this technology.

Project Tasks:

Task 1: Benchmarking of current processes and products.

Task 2. Accelerated development of "batch" processing at ORNL.

Task 3. Define, procure and install a TMP superconducting magnet system for commercial application. Task 4. Develop parameters for continuous processing system.

\subsubsection{Induction Thermomagnetic Processing (ITMP) Configuration}

To satisfy a typical industrial heat treating production requirement, a production-rate capable system specification was made to nominally process 300 6-pound gears per hour. An industrially-robust system requires that the production-rates can be met without any deleterious effects on the ITMP system.

Project Tasks:

Task R1: Develop a LabView ${ }^{\mathrm{TM}}$ software interface and instrumentation for monitoring/detecting appropriate superconducting magnet coil and test sample parameters.

Task R2: Integrate ORNL's commercial prototype TMP system with ATM's large sample induction heating and quenching insert with suitable mass specimen (equivalent mass of HP30 Orbital drive). Task R3: Perform a parametric study on instrumented system. Testing would gradually vary superconducting magnet field strength (from 0.5 to 9.0 Tesla) and sample insertion rate $(0.5$-inch/s to 10 inches/s or until instrumentation detects a pre-magnet-quench event or a superconducting magnet coil quench occurs).

Task R4: Define new superconducting magnet system and induction heating/sample handling system components and diagnostic software for incorporation of pre-magnet-quench event detecting capabilities into future commercial thermomagnetic processing systems.

Task R5: Based on Tasks 3 and 4, revised induction heating/sample handling system components are fabricated and provided by industrial partners to test reduced force and/or reduced $\mathrm{dB} / \mathrm{dt}$ design concepts (therefore reduced magnet quench environment) for incorporation into future next-generation 
commercial prototype systems after evaluation in Task 6.

Task R6: Conduct new parametric tests. Starting at magnetic field strengths of $6 \mathrm{~T}$ (up to 9) and insertion speeds of 4 inches/s (up to 10), test new magnet-quench-prevention integrated heating/sample handling system concepts and improved pre-quench event detection diagnostic system. 


\section{RESULTS AND DISCUSSION: HMFP CONFIGURATION}

Based on the successful results of static/batch experiments and our initial continuous processing experiments, in which ambient temperature high magnetic field processing (HMFP) was shown to reduce the amount of retained austenite and increased the hardness of the razor blank material, additional dynamic processing experiments were conducted. A laboratory-scale system was designed and configured to simulate a continuous processing line. Figure 1 shows the components of the initial set-up during an experimental run using ORNL's original thermomagnetic processing system that did not have incorporated a cryogen-recondensing system to eliminate liquid helium replacement in a manufacturing environment. Through this project, a state-of-the-art 9-tesla, 5-inch diameter horizontal bore superconducting magnet systems with cryogen recondensing capability was designed, built, and installed at ORNL and is shown in Appendix A. The results of the series of experiments run on ORNL's original system summarized in Table 1 not only provided promising results in retained austenite reduction but also highlighted areas where we could improve the experimental setup to more accurately simulate a production process while allowing very accurate control and monitoring of processing parameters during these experiments.
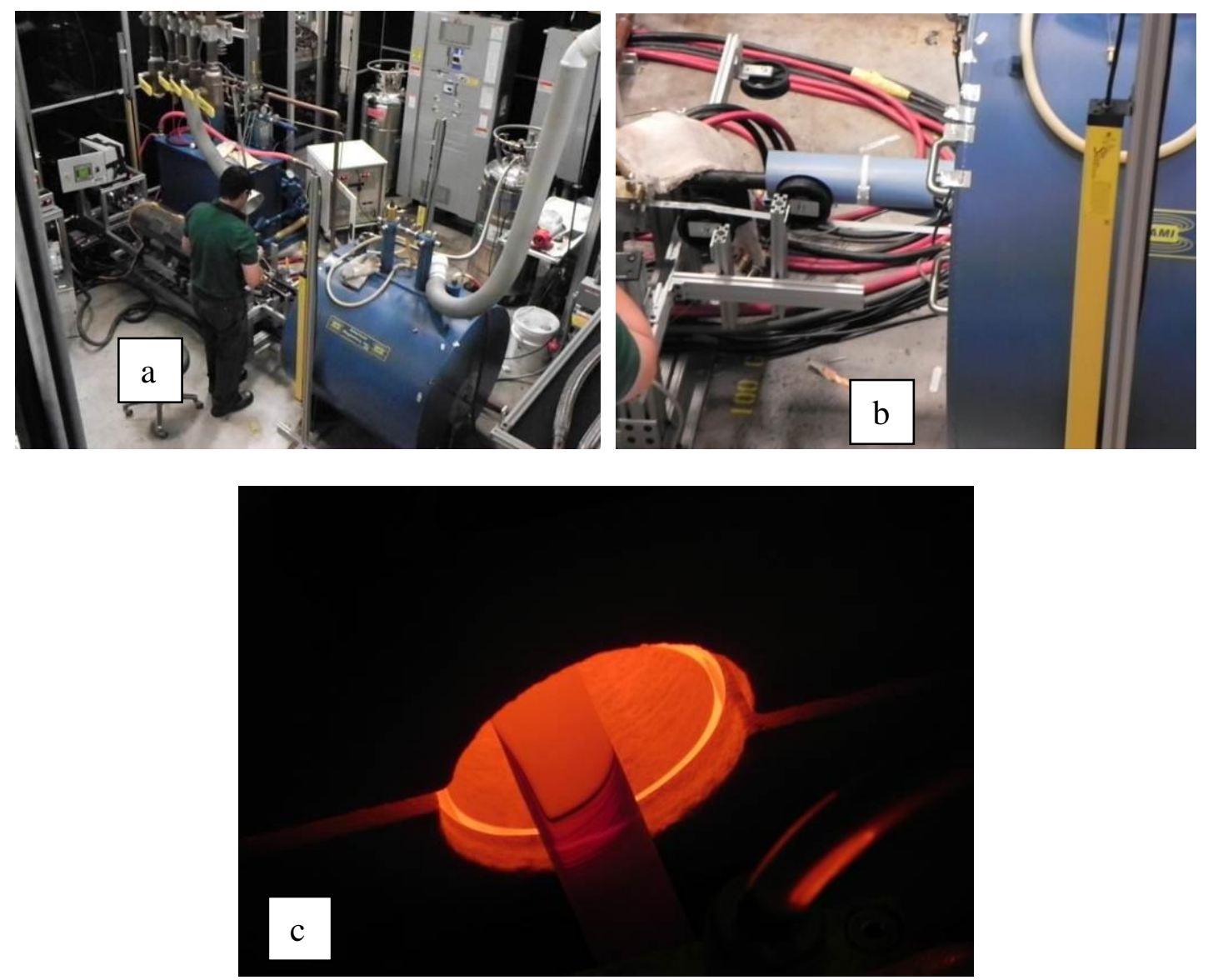

Figure 1. Photos showing the laboratory scale "mocked-set-up" used to simulate the high temperature processing and quench step for a razor blade processing line: (a) shows the razor blade material on the spooler/tensioner entering the furnace, (b) shows the blade as it is exiting the chill blocks and being guided by the pulleys into the entrance of the magnet. (c) shows the blade exiting the furnace before it enters the chill blocks. 
Table 1. Summary of experimental matrix conducted using the initial set-up on razor blank strip to develop processing parameters for continuously processed razor blanks

\begin{tabular}{|l|l|l|l|l|l|l|}
\hline \multicolumn{1}{|c|}{ Sample ID } & Sample ID & $\begin{array}{c}\text { Time @ } \\
\mathbf{1 0 0 0 C}(\mathbf{s e c})\end{array}$ & $\begin{array}{c}\text { Time @ } \\
\mathbf{1 1 0 0 C}(\mathbf{s e c})\end{array}$ & $\begin{array}{c}\text { Quench } \\
\text { block temp } \\
\text { (Celsius) }\end{array}$ & $\begin{array}{c}\text { Field } \\
\text { (Tesla) }\end{array}$ & $\begin{array}{c}\text { Normalized } \\
\text { RA (wt\%) }\end{array}$ \\
\hline A2-30(sec) NF & A2 & 30 & 15 & 1 & NF & 0.00 \\
\hline A3-15(sec) NF & A3 & 15 & 7.5 & 1 & NF & -3.47 \\
\hline A4-10(sec) NF & A4 & 10 & 5 & 1 & NF & -4.94 \\
\hline B5-30(sec) NF-1 & B5 & 30 & 15 & 20 & NF & 3.19 \\
\hline B3-15(sec) NF & B3 & 15 & 7.5 & 20 & NF & 0.63 \\
\hline B4-10(sec) NF & B4 & 10 & 5 & 20 & NF & -1.34 \\
\hline C1-30(sec) 9T-1 & C1 & 30 & 15 & 20 & 9 & 1.76 \\
\hline C3-10(sec) 9T & C3 & 10 & 5 & 20 & 9 & -1.56 \\
\hline C4-15(sec) 9T & C4 & 15 & 7.5 & 20 & 9 & 1.69 \\
\hline D1-30(sec) 9T-1 & D1 & 30 & 15 & 1 & 9 & -4.24 \\
\hline D1-30(sec) 9T-2 & D1 & 30 & 15 & 1 & 9 & -3.04 \\
\hline D2-15(sec) 9T-1 & D2 & 15 & 7.5 & 1 & 9 & -4.66 \\
\hline D2-15(sec) 9T-2 & D2 & 15 & 7.5 & 1 & 9 & -5.00 \\
\hline D3-10(sec) 9T-1 & D3 & 10 & 5 & 1 & 9 & -5.05 \\
\hline D3-10(sec) 9T-2 & D3 & 10 & 5 & 1 & 9 & -5.89 \\
\hline
\end{tabular}

The strip material is pulled through the system by an ORNL designed and fabricated system that incorporates dynamic feedback for speed and line tension control. This unique system was designed to ORNL specifications and is shown schematically in Figure 2. Essentially this system allowed control of line tension and speed dynamically. The need for feedback control of line tension during continuous processing experiments became evident during the experimental runs. This was due mostly because the friction between the quench blocks and strip material varies throughout the experimental run.

Additionally if the quench blocks are removed in between experiments it is important to maintain sufficient line tension to prevent the material from moving into the magnet. This new instrument allowed reproduction of line tension and maintained control of the strip material in-between runs thus allowing for subsequent optimization of the process. 


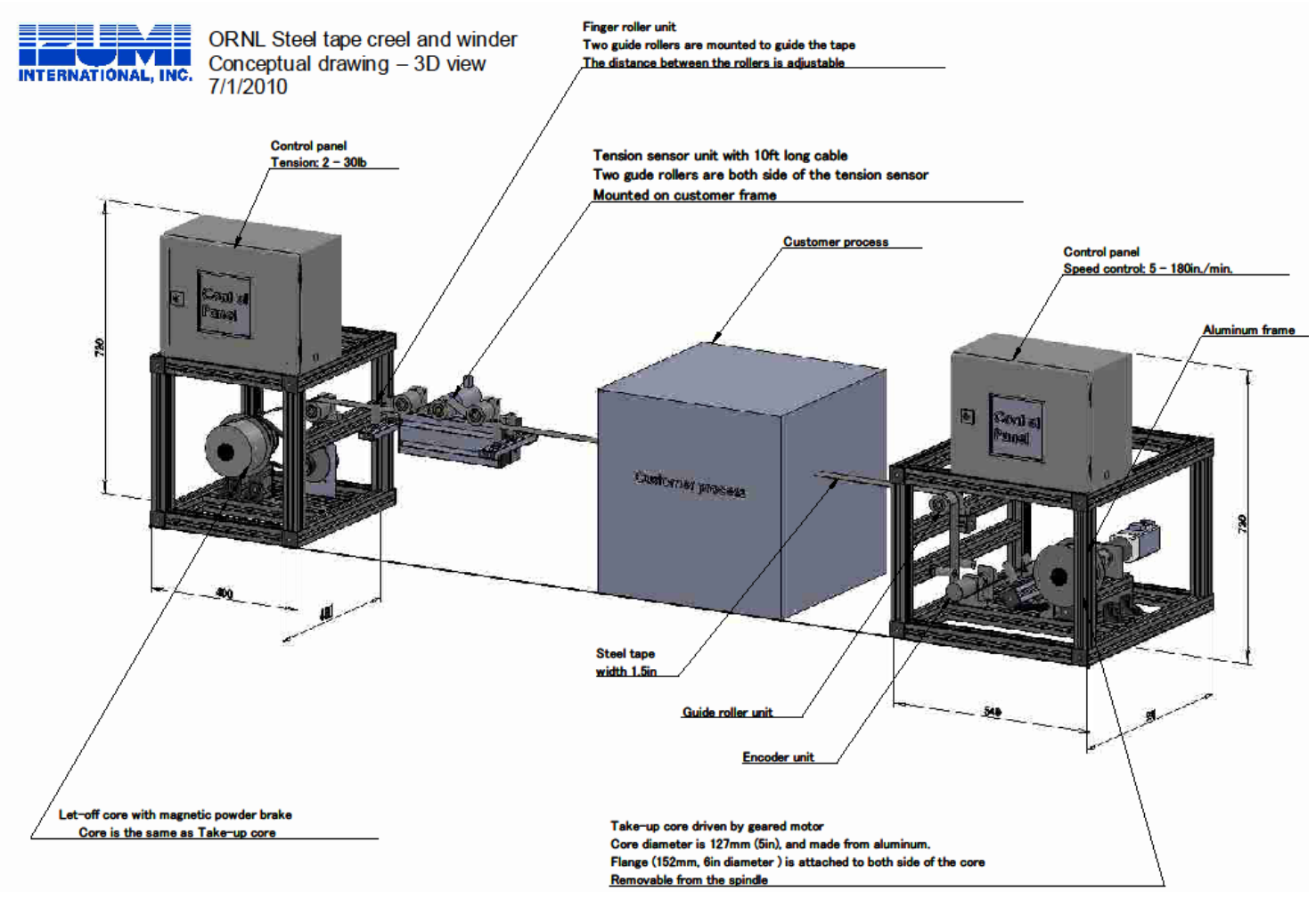

Figure 2. ORNL sample feed system with active line tension and speed control.

For accurate temperature control and monitoring, an ORNL prototype temperature sensor probe was incorporated (Figure 3.) Calculations on the optimal sensing distance were made for various sensing configurations. One such configuration involved the use of a reference light source to monitor the changing reflectivity of the metal strip.

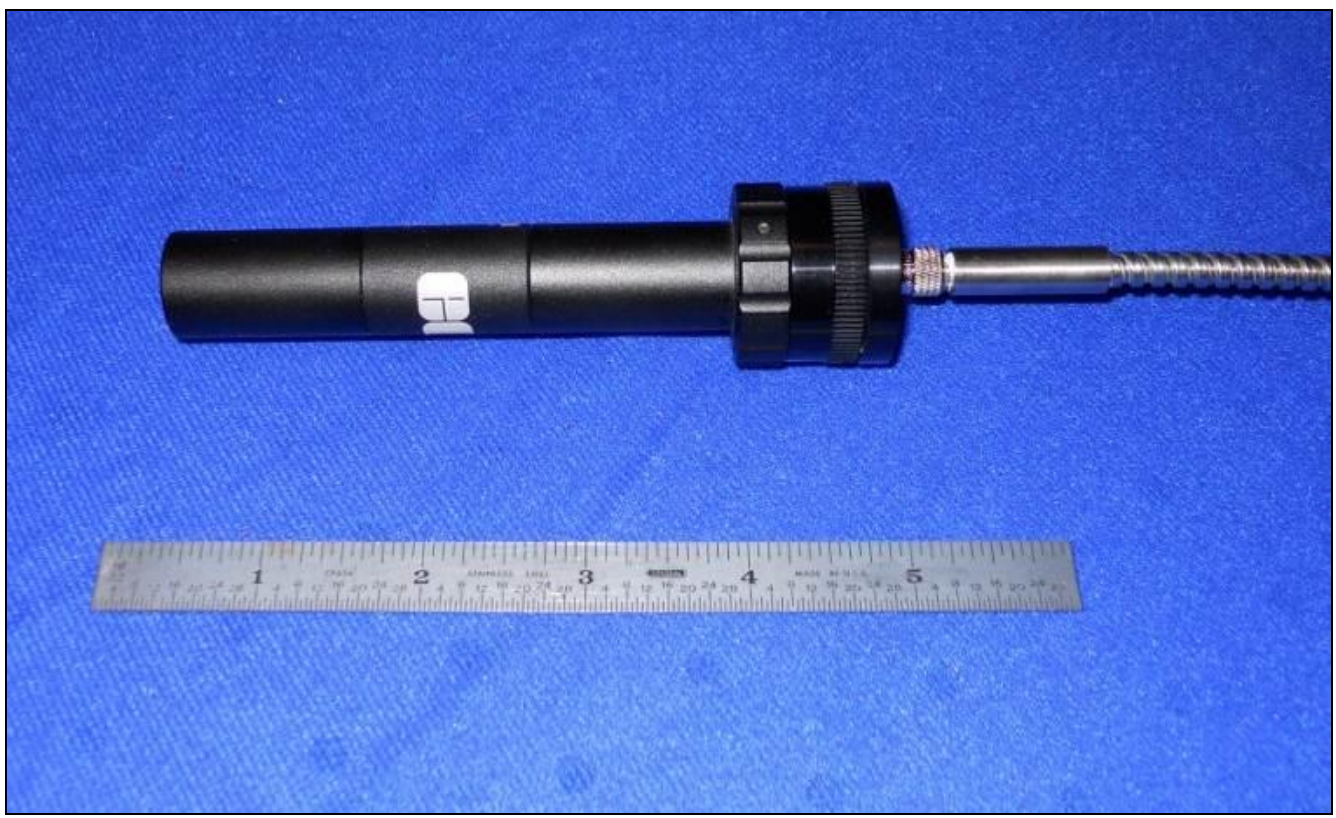

Figure 3. Side View of Optical Temperature Sensing Probe (with optical fiber connected). 
The optical probe in the temperature sensing system was a telecentric design with the entrance and exit pupils at infinity. Such systems are often used in metrology because they reduce the measurement or position error due to defocusing. For certain configurations of the ORNL probe, the working distance from the target to the objective lens must satisfy simultaneous imaging requirements for emissivity compensation, and collecting and relaying spectral radiance from the band. These constraints require operating the optical system in and out of focus condition.

The proprietary optical prescription for the three-group, 5-element system was obtained from Edmunds Scientific and ray-traced to:

1. Verify that the object-image relationships were consistent with the system specifications under vendor conditions

2. Estimate the revised working to image the $600 \mu \mathrm{m}$ transmit fiber output to a $3 \mathrm{~mm}$ spot at the band

3. Refine the working distance to re-image the $3 \mathrm{~mm}$ spot onto the outer annulus of receiving fibers (1.8 $\mathrm{mm}$ diameter).

Satisfying these conditions reduced the initial $113 \mathrm{~mm}$ working distance to about $42 \mathrm{~mm}$. The same approach was used with the Sekidenko 4000E system to verify the vendor's recommendation of a 6inch working distance.

For configurations employing in-focus measurements, a calibration test was performed to evaluate the systems performance. The ORNL probe was positioned to measure the temperate of a Hart Scientific 9132 Infrared Calibrator "graybody" source as "truth," with accuracy $<\sim 0.5 \mathrm{C}$ (in the 400 to $500^{\circ} \mathrm{C}$ temperature range) verified by the ORNL Metrology Group (G. Strickland). Data showed good agreement between the two sources.

A 4000E pyrometer was integrated since there was sufficient room and access to integrate both the Sekidenko and ORNL probes to simultaneously monitor temperature at the exit of the heater and input to the chiller block, respectively. The heater measurement was critical to verify the requirement for annealing; it must be measured "in" the heater before oxidation occurs as the band exits. In practice, the spatial structure of the oxidation can create problems in accurately measuring emissivity to infer temperature.

Figure 4 shows the notional design of the system to measure the band temperature as it exits the heater. Very few modifications were needed to the original system configuration. A small, rectangular insulator block was mounted on the stainless bracket. The probe was mounted through a hole drilled in the insulator and bracket. The insulator required an additional inner liner since additional thermal isolation was needed around the stainless steel probe body which contained the relay optics. An axial adjustment of the probe allowed some variation about the nominal working distance. An additional oversized hole was drilled through the thermal insulation for clear line-of-sight from the probe objective lens to the moving band. The probe's 1.75 degree full field-of-view collected thermal radiation within a $0.5 \mathrm{~cm}$ diameter spot at the 6 -inch working distance. The sample rate for the probe to provide time-correlated measurements was selected to accommodate the steel strip band speed ( 90 $\mathrm{ft} / \mathrm{min}$ ) and track temperature variation/uniformity accurately. 


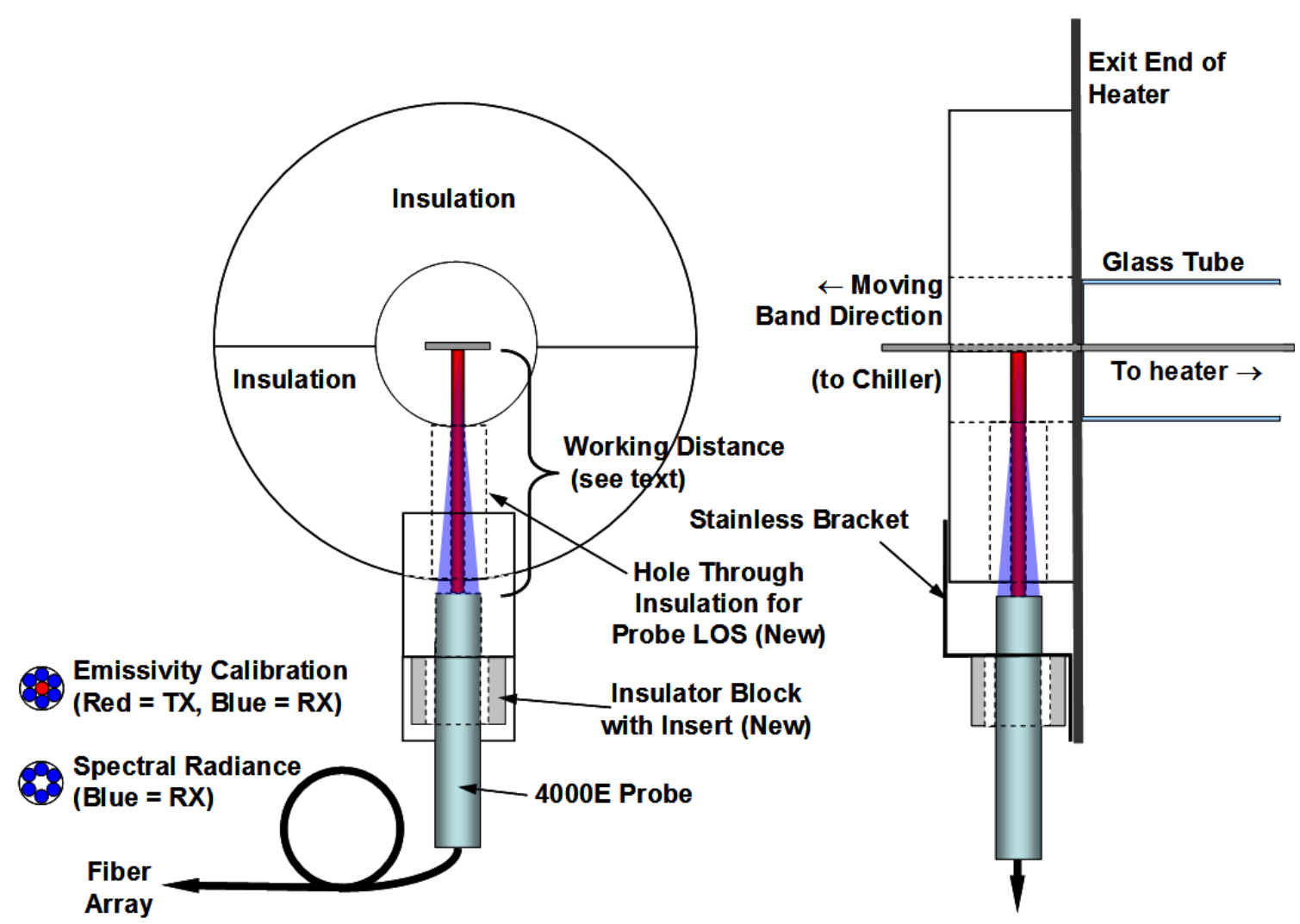

Figure 4. Notional mount design for the $4000 \mathrm{E}$ probe.

Additionally the lab scale system was configured for a large scale run as summarized in Appendix A, Figures A1-A10. This system is capable of fully heat-treating 500 feet of strip material in a continuous process while maintaining accurate process strip feed speed and tension on the steel strip.

A series of neutron scattering experiments at the Spallation Neutron Source (SNS) were conducted to determine the difference in final phase distributions and residual stresses between the cryogenically treated standard materials and those treated by TMP. The materials were tempered while undergoing high temporal resolution in-situ neutron diffraction experiments to reveal phase fractions and the evolution of the residual stress states.

Three batches of C:0.67\%; Si:0.4\%; Mn: 0.65\%; Cr: $13.0 \%$ steel strip material were prepared prior to neutron scattering experiments. These materials were treated in the following conditions: 1) heat-treat at $1200 \mathrm{C}$ and water quenched (WQ), 2) heat-treat at $1200 \mathrm{C}$ and (WQ) followed by a cryogenic quench and 3) heat-treat at $1200 \mathrm{C}$ and (WQ) followed by a 9T magnetic field treatment. Materials given the thermal paths described in (1-3) were prepared in batches prior to the neutron scattering experiments. Tempering of these materials was performed in the VULCAN instrument at temperatures nominally at $300 \mathrm{C}$ for no more than one hour.

In order to maximize the use of beam time at the SNS several texture free samples were prepared. These samples were vacuum arc melted and drop cast into a rectangular 1"X2"4" mold. These materials were sectioned and heat-treated at $400 \mathrm{C}$ in order to replicate the baseline microstructure. Subsequent characterization confirmed the composition and microstructure. These materials were used for the three processing path experiments outlined above. 
All measurements were made in the VULCAN instrument at SNS with a furnace situated within the beamline. All measurements were made using two samples simultaneously mounted in orthogonal directions (orthogonal strain method). Materials (1-3) were aligned in beamline and the as-treated phase fraction and residual stresses across the sample were measured. Samples (1-3) were heated to $300 \mathrm{C}$ with in-situ measurements of the phase fractions and the evolution of the stress states.

The results of the neutron scattering experiments are shown in Figures 5 and 6 . The analysis for sample path 1 (austenitized and quenched (water) are shown in Figures 5 a, b and c. Figure 5a shows the lattice parameter for both the martensite (BCT) and the retained austenite (FCC) while Figure 5b shows the c/a ratio for the martensitic phase. A surprising result is that there is significant carbon movement linked to an abrupt structural change at temperatures below 100C. As seen in Figure $5 \mathrm{~b}$ the c/a ratio for the martensite is reduced from 1.0175 to 1.009. Figure 5C shows the rsca parameter (defined below) for the austenite. The rsca parameter is linked to the residual stress state of the material through the displacement of the lattice from its equilibrium position. It is defined by the following equations:

$$
\begin{aligned}
& A_{h k e}=\frac{h^{2} k^{2}+k^{2} l^{2}+l^{2} h^{2}}{\left(h^{2}+k^{2}+l^{2}\right)} \\
& \varepsilon_{h k e}=\frac{\underbrace{d_{h k e}-d_{h k e}^{\circ}}_{\text {Isotropic }}-\gamma \underbrace{d_{h k e}^{\circ}}_{\text {Anisotropic }} \quad \gamma=r s c a}{\underbrace{}_{h k a}}
\end{aligned}
$$



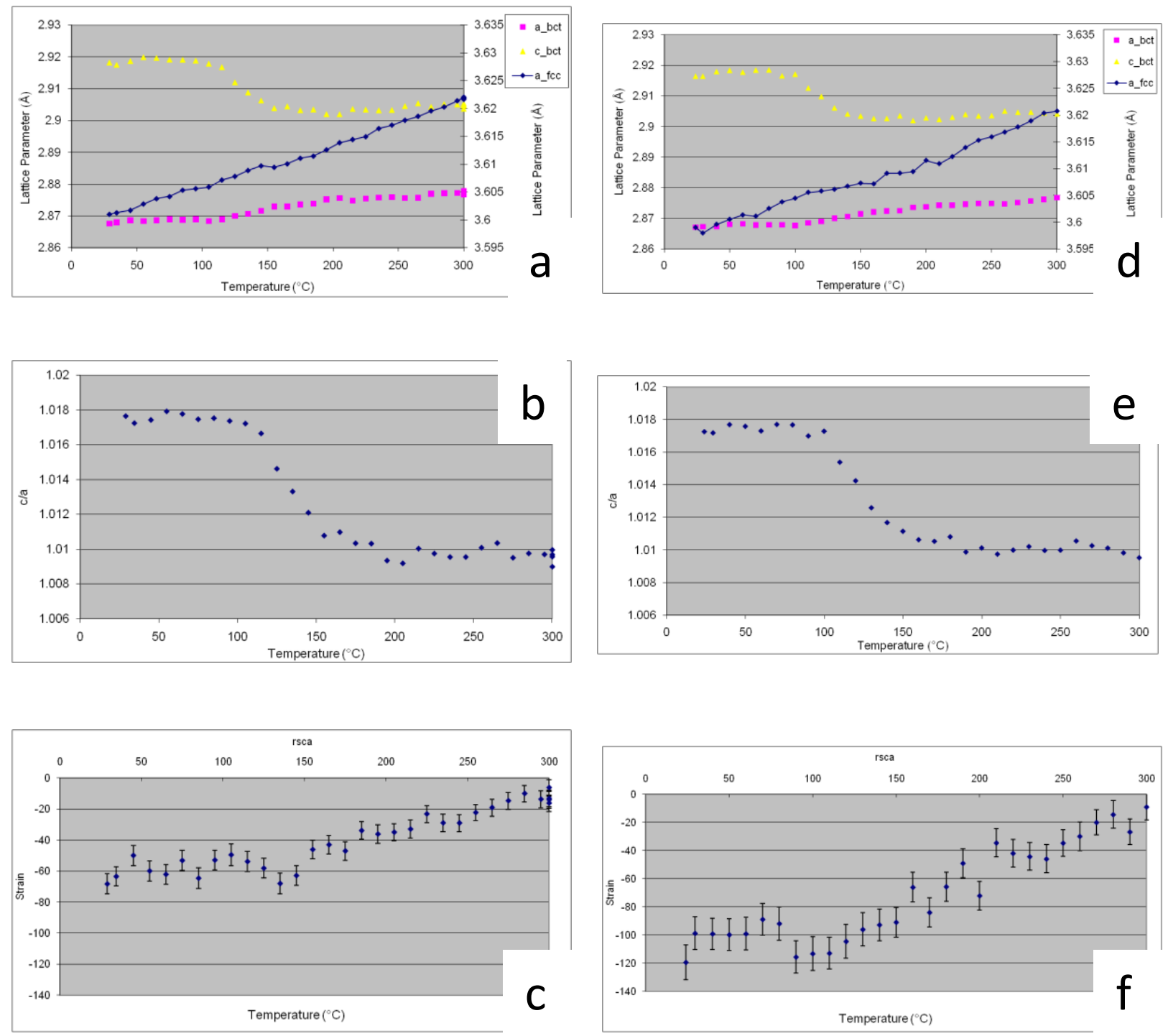

Figure 5. Structural analysis of a, b, c) austenitized and quenched sample and a magnetically processed sample d, e, f. during tempering.

Figure 5C shows that by 300C most of the residual stresses have been relieved during the tempering process. Similar results are shown for the samples that were magnetically processed after austenitization (path 3) and quench in Figure $5 \mathrm{~d}$, e and f. Again there is a significant change in the crystal structure at relatively low temperatures although the amount of retained austenite decreased from 40 wt. \% to 16 wt. \% from Rietveld analyses of the neutron data. Additionally the residual stress was slightly higher than in the as quenched samples, which is an expected finding due to the Baine distortion associated with the movement of the habit plane across the austenite/martensite interface. This is evident in the rsca decreasing from -60 to -100 .

Figure 6 shows the analysis of the cryo treated materials given the conventional heat treatment (path 2 ). In this experiment the residual stress is significantly higher than in the magnetically processed materials at comparable levels of retained austenite. Comparison of Figure $6 \mathrm{~F}$ and Figure $5 \mathrm{~F}$ reveals that the residual stresses in magnetically processed materials are relieved at a temperature that is at least $100 \mathrm{C}$ lower in comparison to the cryo-quenched materials as the strain approaches zero in the Figure 5F before $250 \mathrm{C}$ while still rather large (-100 microstrains) strain exists above 300C. 

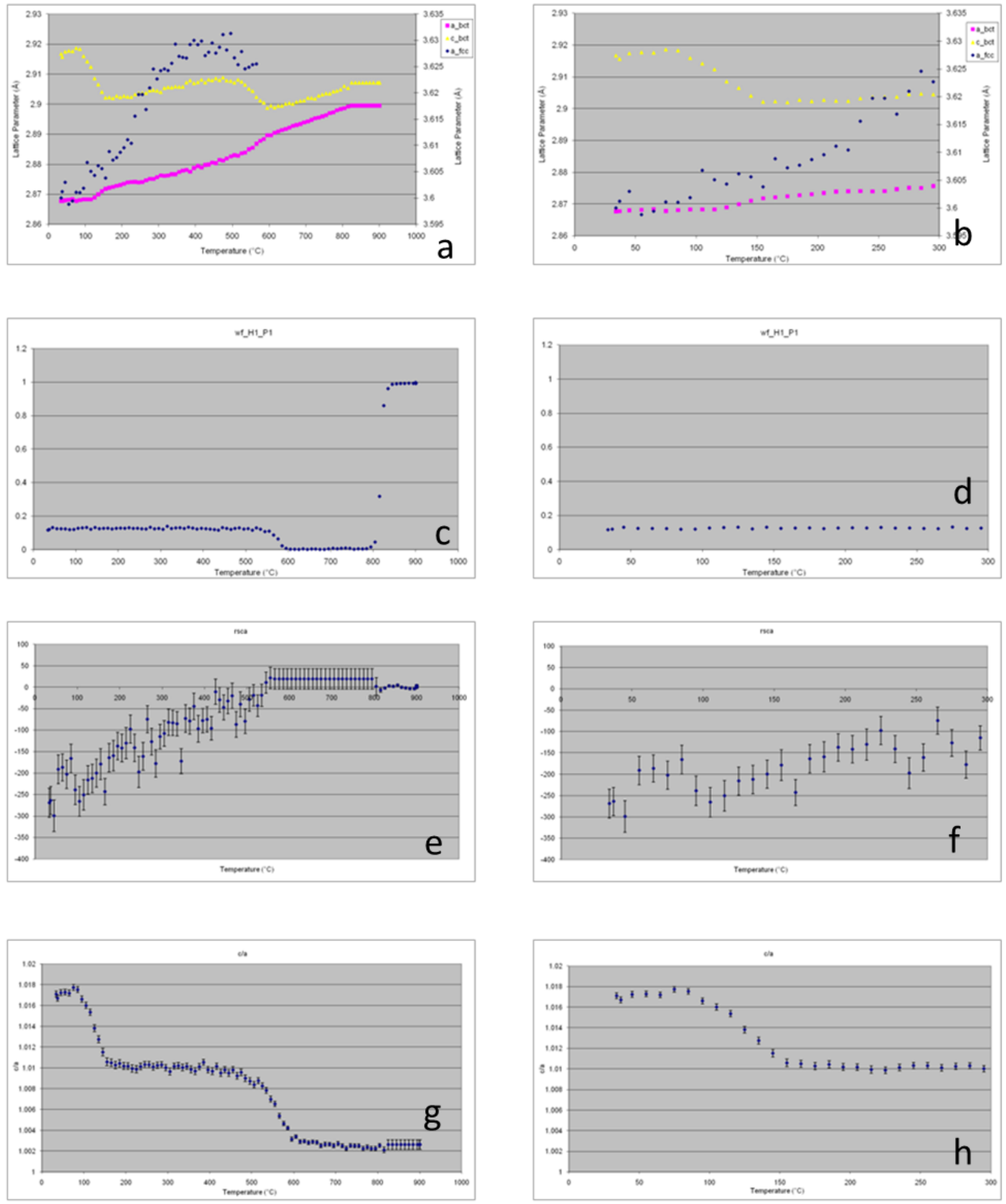

Figure 6. Structural analysis of a cryo-quenched sample during tempering.

The cryogenically treated sample was heated to $900 \mathrm{C}$ and the full transformation path was examined. Following the initial structural rearrangement at low temperatures there is a second structural rearrangement in the martensite. This first rearrangement was linked with carbon diffusion within the martensite's lattice while the second structural change was linked to carbon diffusing out of the 
martensite. A final structural change occurs upon the dissolution of the austenite and the c/a ratio approaches 1 . At this point the martensitic structure transforms to the equilibrium bcc phase. Further heating results in the dissolution of the bcc phase as predicted by equilibrium thermodynamics. Although this study could benefit from further experiments that maximize use of the high temporal resolution available on VULCAN, the results reveal that for the TMP materials, the tempering temperature may be reduced by up to $100 \mathrm{C}$ and still relieve residual stresses while allowing for carbon diffusion.

It is important to the current laboratory study to accurately reproduce the time the strip material dwells at elevated temperatures during the austenitization heat treatment. In order to accomplish this in a laboratory setup the strip material "feed rates" were slowed down. In order to optimize this technology for the integration in to a commercial process two interrelated variables were investigated that provide a model to predict microstructure based on dwell time at elevated temperature and water quench block temperature. For the test matrix the furnace profile was maintained constant and only the strip material speed and the quench block temperatures were varied. The furnace was set with two zones at 1000C and a third zone at 1100C which is approximately the thermal profile of an industrial furnace. The test matrix described here is therefore designed to investigate the interrelation between the solution treatment time and the resulting microstructures as well as the effect of quench block temperatures on the resulting microstructure before and after magnetic processing.

X-ray diffraction analysis of the phase fractions of carbides and retained austenite was performed on the thermomagnetically processed materials and compared to baseline conventionally processed strip material. The results from the first set of continuous processing experiments are given here for reference. XRD Rietveld analysis was performed on the baseline strip material using the analytical setup described in Table 2. The resulting normalized retained austenite phase fraction analysis is summarized in Table 1. It is important to note that some error was found due to significant crystallographic texture.

Table 2. Experimental conditions of the $X$-ray measurements with the 4-circle diffractometer

\begin{tabular}{ll}
\hline Parameter & Condition \\
\hline Equipment & Scintag PTS goniometer \\
& Spellman DF3 series $4.0 \mathrm{~kW}$ generator \\
Power & Scintag liquid $\mathrm{N}_{2}$-cooled Ge detector \\
Radiation & $1.44 \mathrm{~kW} 40 \mathrm{kV}, 36 \mathrm{~mA}$ \\
Incidence divergence & $\mathrm{Co}, \lambda K \alpha=1.78897 \AA$ \\
Receiving slit acceptance & $0.3^{\circ}$ \\
& $0.25^{\circ} ;$ radial divergence limiting parallel plate \\
Goniometer radius & collimator \\
Axial Soller slit divergence & $290 \mathrm{~mm}$ \\
$\theta-2 \theta$ Scans & $\pm 1.7^{\circ}$ \\
\hline
\end{tabular}

Quantitative XRD work is usually done on randomly oriented samples as it is strongly influenced by texture. Recent prior quantitative phase identifications with XRD were accomplished using the Rietveld Analysis (Young, 1995), and all Rietveld refinements were conducted using High Score Plus (2009). Today Rietveld codes have limited provisions for dealing with textured data and are based on work by Dollase (1986). For this work using Rietveld Analysis, the Dollase-based model and other strategies to overcome this texture are still being addressed however the work of Miller (1968) provides a detailed insight into this very problem.

Measurement of the fraction, grain size, and crystallographic texture of the ferritic (or martensitic) 
matrix, the RA, and carbides (if present) is essential to understanding the steel processing-properties relationships. EBSD is a good approach, but RA-containing steels are a difficult problem. The thermomagnetically processed $\mathrm{Fe}-13.0 \mathrm{Cr}-0.65 \mathrm{Mn}-0.4 \mathrm{Si}-0.67 \mathrm{C}$ (wt\%) steel hot-rolled thin strip was found via X-Ray Diffraction (XRD) to contain ferritic/martensitic matrix, RA, and M23C6 carbides. However, overlapping X-ray peaks and strong texture made it difficult to precisely determine RA volume fraction, which is a vital metric to compare processing paths.

Electron backscatter diffraction (EBSD) was performed on colloidal silica polished material in a JEOL6500F SEM with Energy Dispersive Spectroscopy (EDS). Figures 7a, 7b and 7c show the SEM image, the phase map, and the confidence index (CI), respectively. Clearly, the phase map in Fig. $7 \mathrm{~b}$ is meaningless, with ferrite and M23C6 giving $45 \mathrm{vol} \%$ each, and the CIs in 1c are poor. Because all three phases are cubic, the patterns are very similar and the EBSD algorithm is unable to find the unique indexing solutions despite using a large number of Hough peaks (12-15) for indexing.
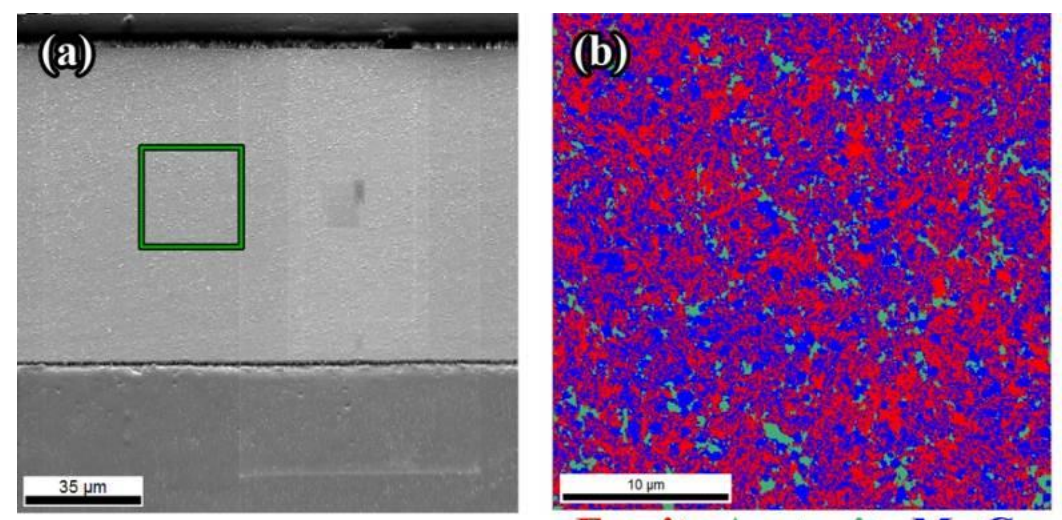

Ferrite Austenite $\mathbf{M}_{23} \mathbf{C}_{6}$

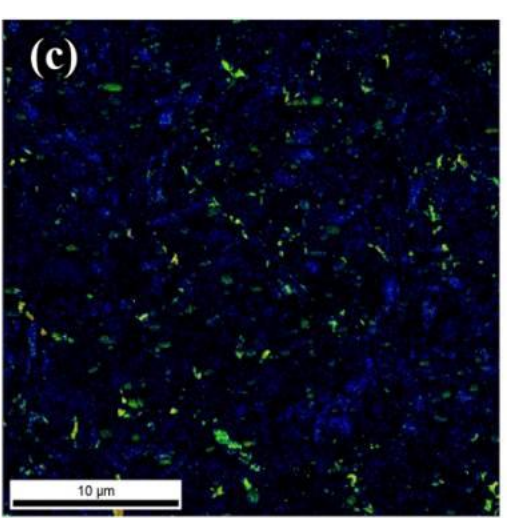

Figure 7. (a) SEM image of polished sample. Box indicates $30 \times 30 \mu \mathrm{m}$ EBSD scan area. (b) EBSD phase map without using chemical information. (c) Confidence index map without using chemical information.

However, the image quality map data shown in Figure 8 were acquired with simultaneous acquisition of $\mathrm{Si}, \mathrm{Cr}, \mathrm{Mn}$, and $\mathrm{Fe} \mathrm{X}$-ray dot maps using an EDS silicon drift detector. Fig. 8a shows an image quality (IQ) map, and Fig $8 \mathrm{~b}$ and $8 \mathrm{c}$ show the Fe and Cr X-ray maps. (The Mn map was dominated by $\mathrm{Cr} \mathrm{K} \beta$ overlap, and the Si map by polishing debris in the surface relief, so $\mathrm{Mn}$ and $\mathrm{Si}$ and not considered further.) Figure 8d shows a red-blue-yellow-magenta map of four partitions identified by statistical analysis using EDS OIM software of the Cr, Fe, and IQ maps. The Hough peaks were then re-indexed offline with the red partition restricted to ferrite + austenite, yellow to austenite+M23C6, and blue and magenta to M23C6, M7C3, and Fe3C. Fig. 9a shows the re-indexed phase map and Fig. $9 \mathrm{~b}$ the $\mathrm{CI}$ map. The RA is $\sim 7.1$ area\%, a qualitatively reasonable number. The $\mathrm{M} 7 \mathrm{C} 3$ and $\mathrm{Fe} 3 \mathrm{C}$ are both $\sim 1$ area\%, which could indicate they are not really present but are simply misindexing artifacts. Clearly, the indexing in Fig. 9a is much more consistent and the confidence (9b) is much higher compared to Fig 7. This new analyses methodology has proven to be a reasonable approach for the problems of cubic carbides in a matrix of ferrite/martensite and austenite. 

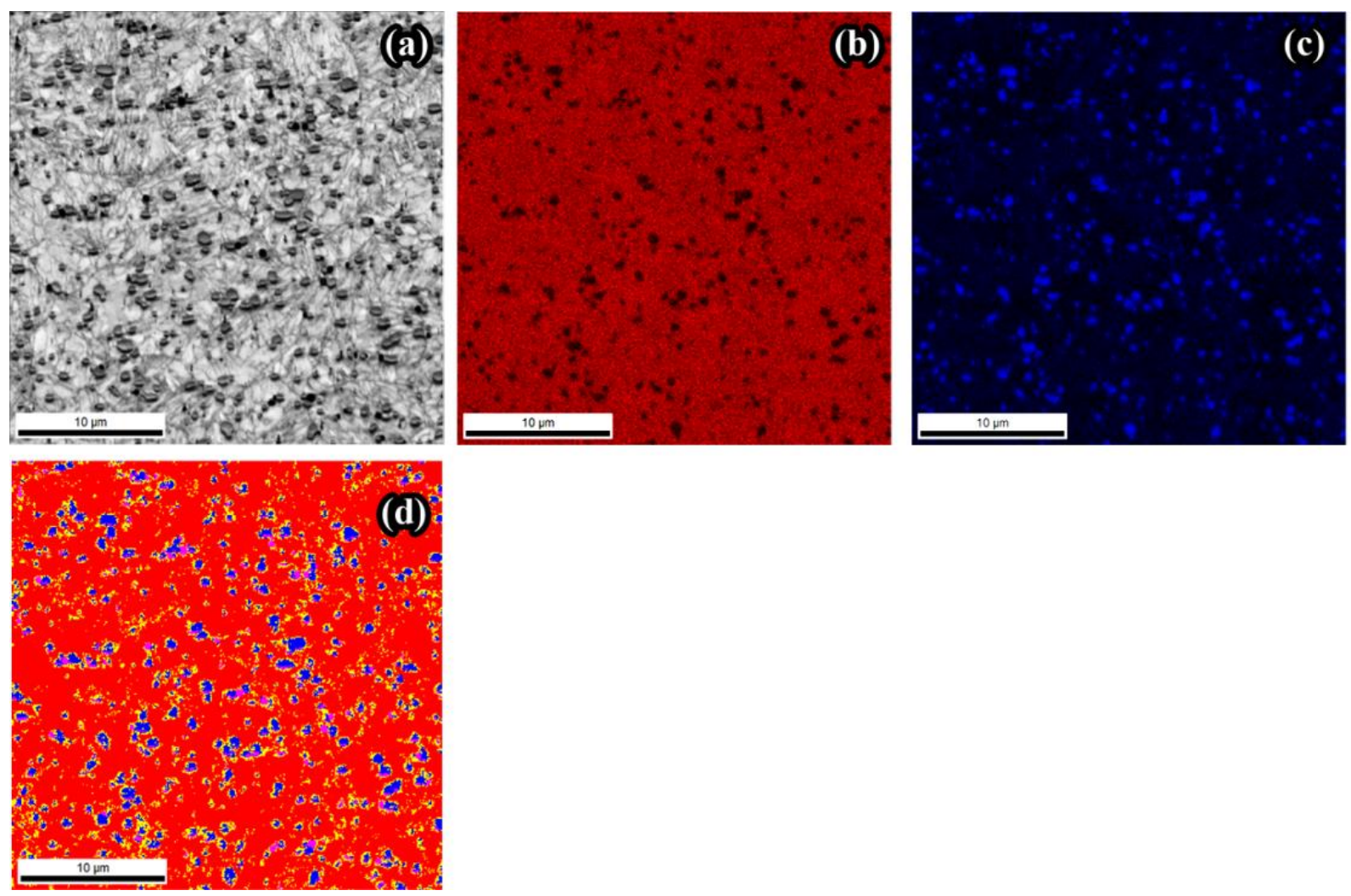

Figure 8. (a) Image quality map. (b) Fe X-ray map. (c) Cr X-ray map. (d) Automated partitioning of the $\mathrm{IQ}+\mathrm{Fe}+\mathrm{Cr}$ maps into four regions for re-indexing.
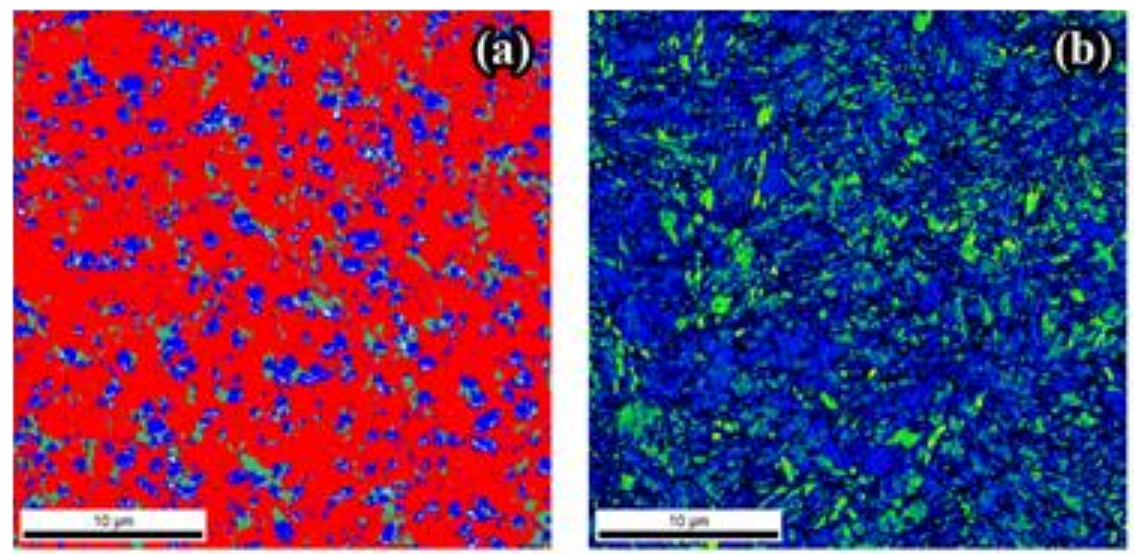

Ferrite Austenite $\mathrm{M}_{23} \mathrm{C}_{6} \mathrm{M}_{4} \mathrm{Fe}_{3} \mathrm{C}$

Figure 9. (a) Re-indexed phase map using chemical information. (b) Confidence index map using chemical information.

A series of data for the "water blocks at room temperature (RTWQ) and chilled water (LTWQ)" samples are shown in Figures 10-13 and reveal the effect of several advanced processing parameters. The retained austenite is normalized to sample A2 by a linear offset. Figure 10 shows the effect of austenitization hold time and two quench block temperatures. Essentially this figure shows that longer hold times results in more carbide dissolution. The available carbon stabilizes the austenite thus resulting in more retained austenite. Additionally this figure reveals that quenching with slightly chilled water significantly reduces the amount of retained austenite. 


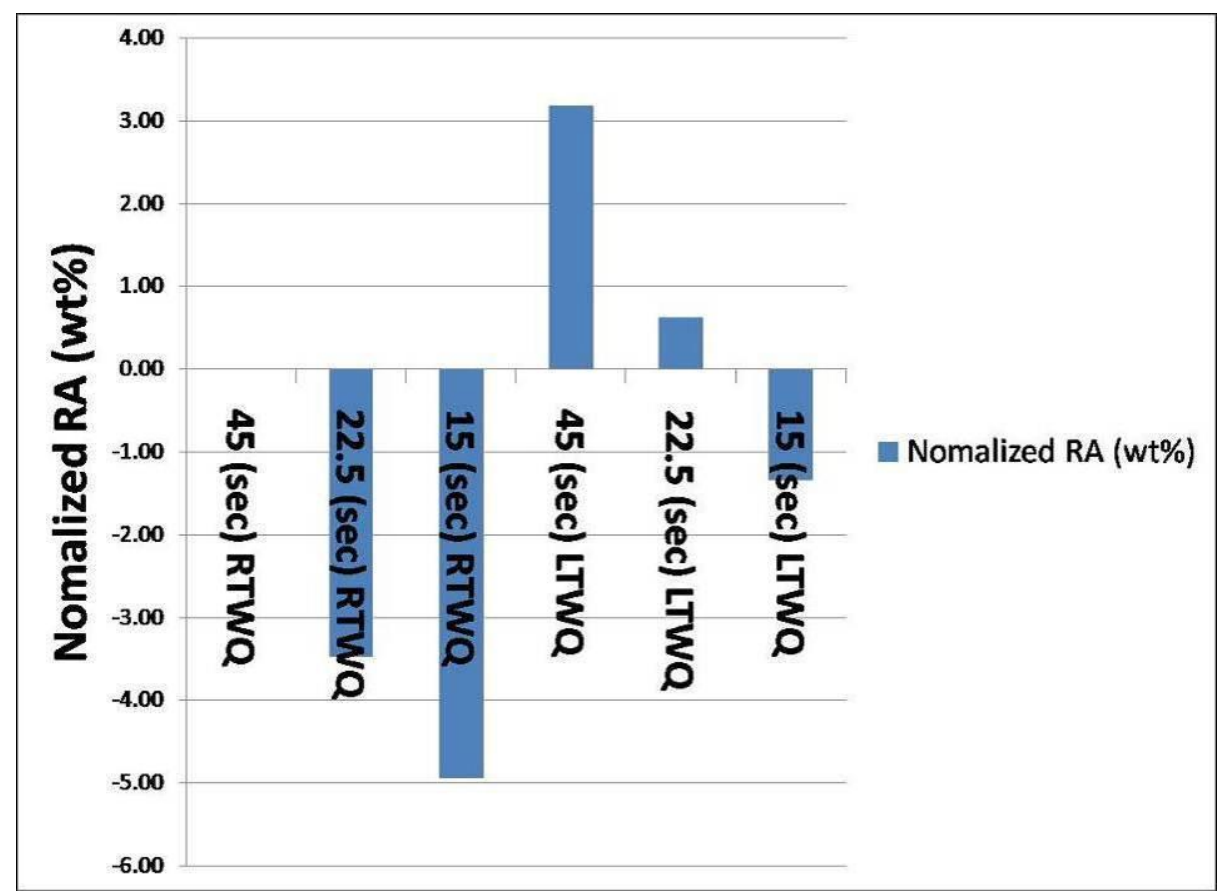

Figure 10. Plot showing the amount of retained austenite after quenching for several austenitization times and water blocks at room temperature (RTWQ) and chilled water (LTWQ).

Figure 11 shows how much retained austenite is converted to martensite by magnetic processing at 9 Tesla. An important result revealed in this analysis is the amount of retained austenite converted to martensite by magnetic processing is not only dependent on the initial amount of retained austenite but is also dependent on the quenching conditions as seen from hardness data presented in Figure 12 and the before and after RA data shown in Figure 13. An important criteria for a commercially viable process is that the production of consistent results. In the most recent phase of this study we have observed that the amount of retained austenite converted by magnetic processing is linearly dependent on the initial amount of retained austenite. To illustrate this effect Figure 13 is shown here. This figure shows that as the amount of retained austenite decreases so does the amount that is converted by magnetic processing. What makes this quite important is that this relationship provides a mechanism to yield more consistent microstructures. That is variations on microstructures are quite common in industrial process are now mitigated by magnetic processing. Essentially, in this application, magnetic processing was shown to reduce the variation in materials with microstructures differing by over $5 \%$ wt\% RA down to less than a percent. 


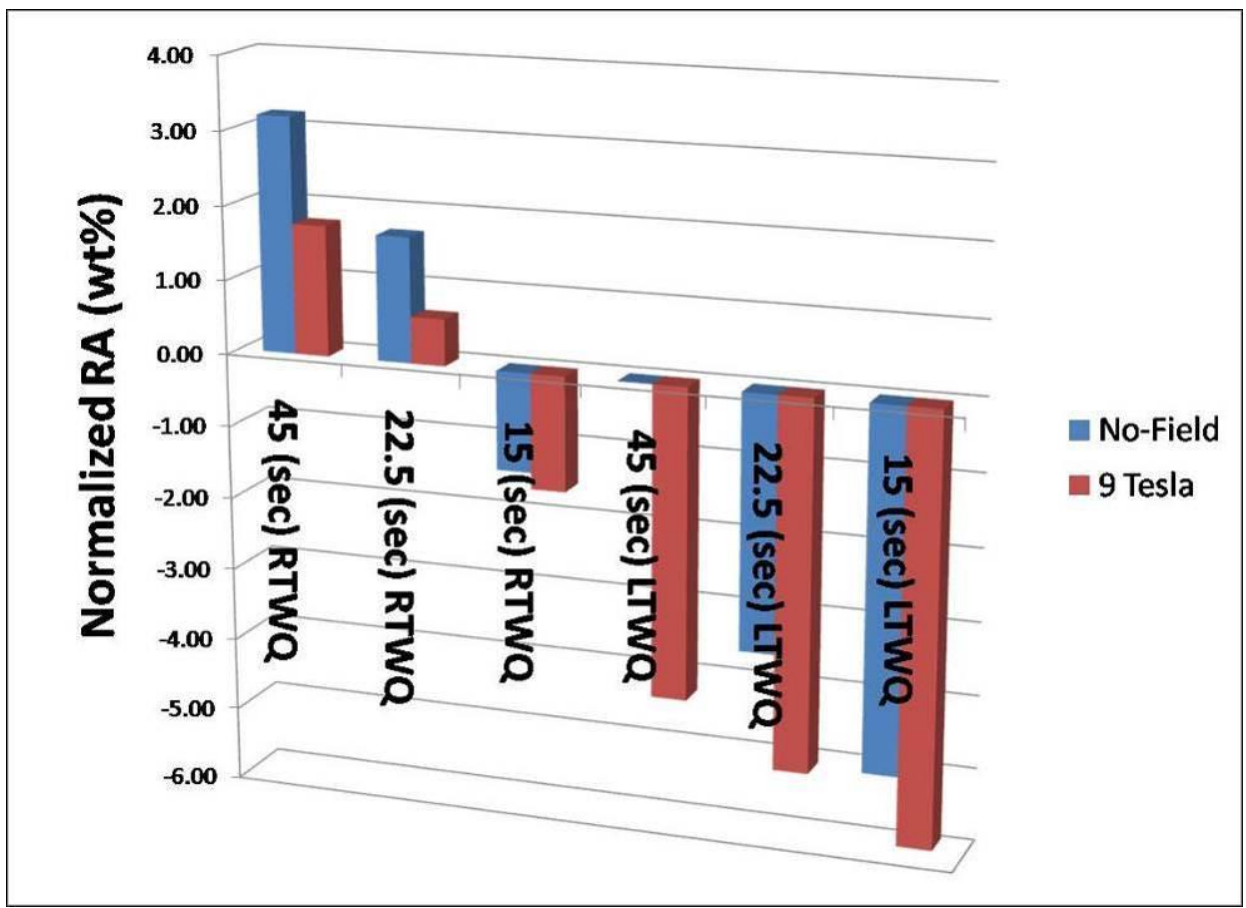

Figure 11. Plot showing the amount of retained austenite before and after magnetic processing at 9 Tesla for the heat treatment matrix.

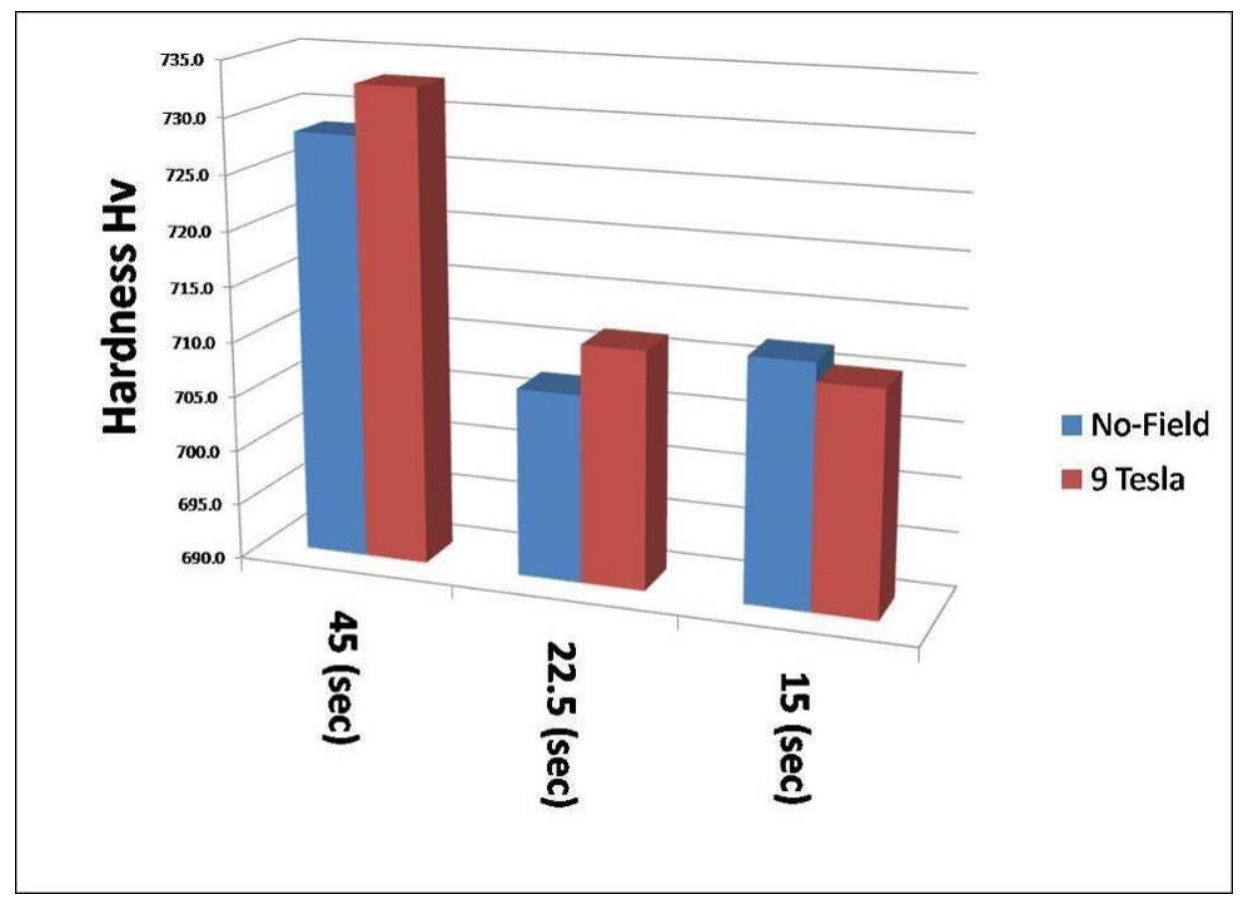

Figure 12. Plot showing the Vickers hardness before and after magnetic processing at 9 Tesla for the heat treatment matrix. 


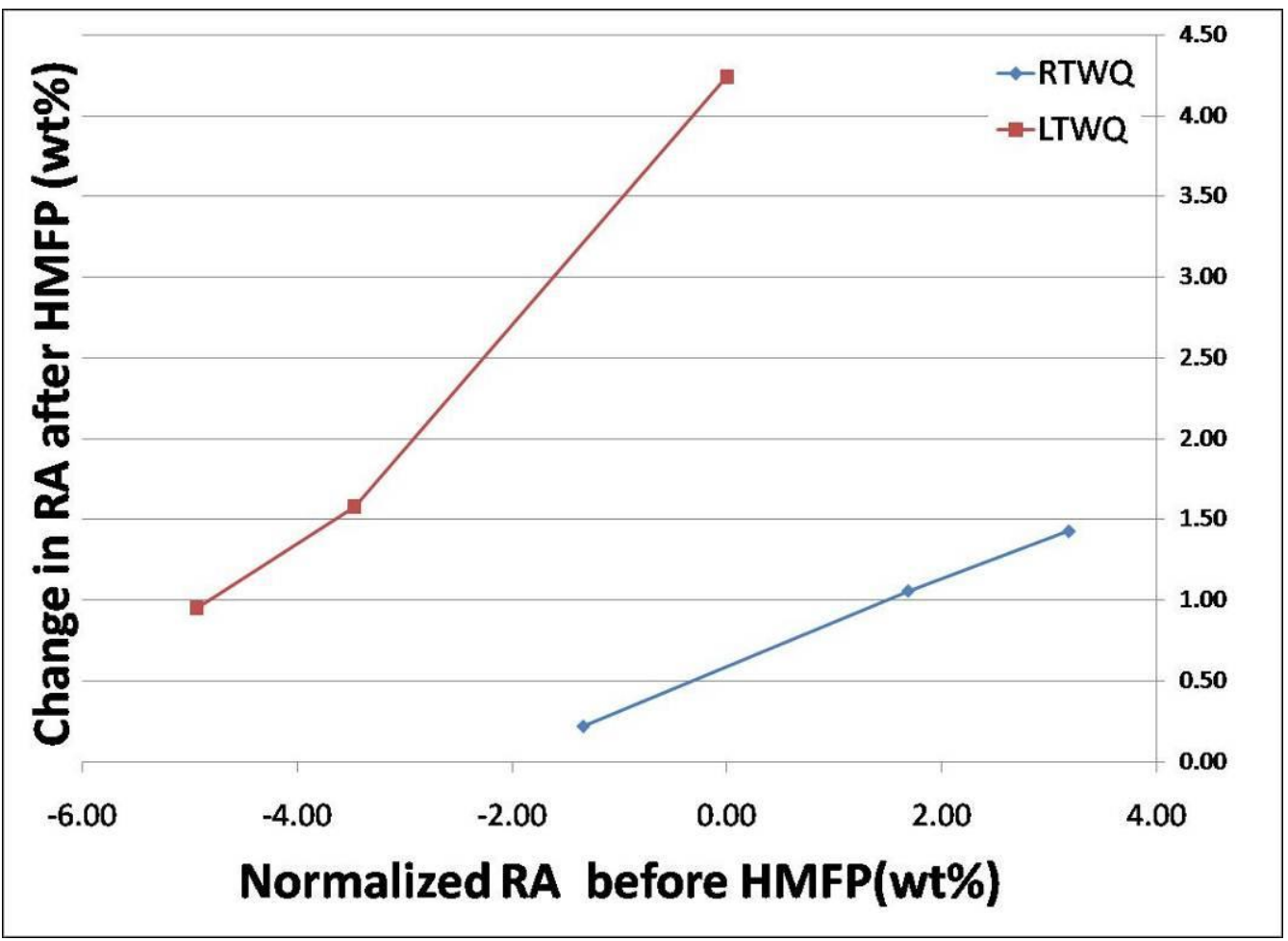

Figure 13. Plot showing the relationship between the initial retained austenite before magnetic processing and amount of retained austenite converted by high magnetic field processing.

A schematic of the combined EDS-EBSD analytical technique is shown in the lower part of Figure 14 while the upper schematic demonstrates the similarity of the EBSD patterns obtained from the carbide and ferrite phases but very dissimilar from the austenite phase EBSD pattern. This analytical technique was applied to the conventionally processed razor blade material. A typical analytical micrograph of the razor blade materials is shown in Figure 15-17. In figure 15 this sample is austenitized, water quenched and subsequently cryo-quenched. In this micrograph the carbides are shown in blue while the retained austenite is shown in green. Similar micrographs are shown for samples B5 and D3. Sample B5 is austenitized and water quenched while sample D3 is austenitized, water quenched and then passed through a 9T magnetic field. Comparison of baseline material and sample D3 reveals that the TMP process is superior at transforming retained austenite. One interesting note is that there are multiple compositions of retained austenite phase. That is austenite between martensitic laths and the alloy rich austenite adjacent to the carbides. Analysis reveals that the austenite that is rich in alloy element does not transform after the water quench however, this austenite is effectively transformed by the high magnetic fields. 

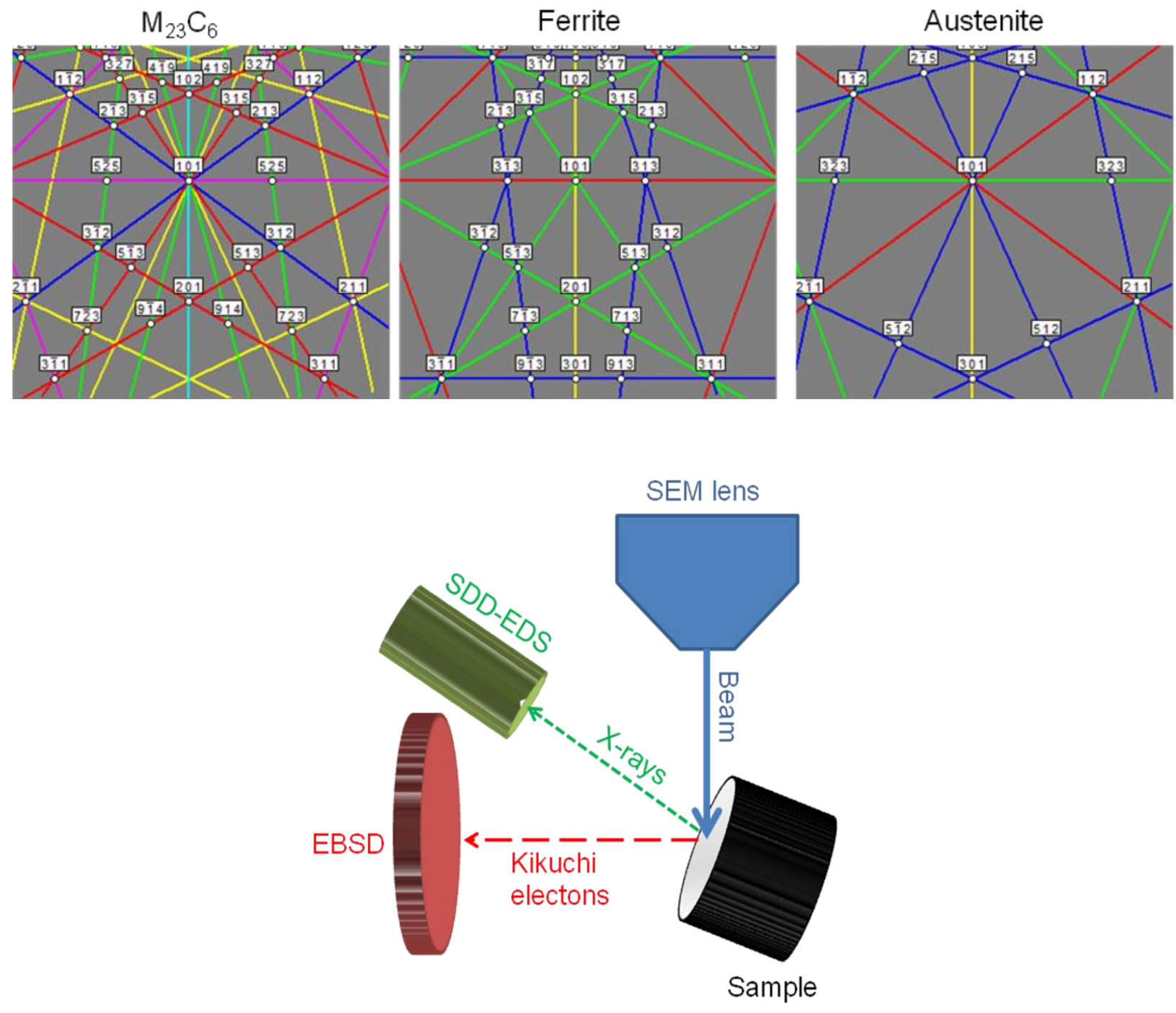

Figure 14. Carbides are structurally similar to the ferrite and dissimilar from austenite. The combined EBSD and EDS technique are shown here. 

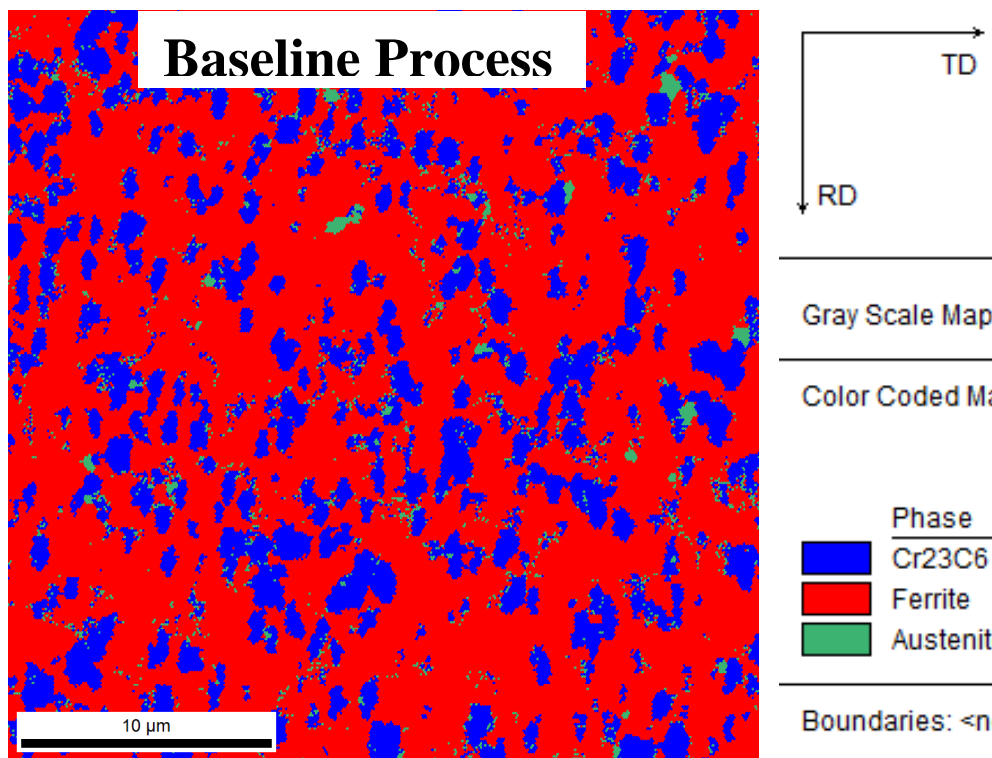

Gray Scale Map Type:<none>

Color Coded Map Type: Phase

\begin{tabular}{|c|c|c|}
\hline Phase & $\begin{array}{l}\text { Total } \\
\text { Fraction }\end{array}$ & $\begin{array}{l}\text { Partition } \\
\text { Fraction }\end{array}$ \\
\hline$\overline{\mathrm{Cr} 23 \mathrm{C} 6}$ & 0.231 & 0.231 \\
\hline Ferrite & 0.738 & 0.738 \\
\hline Austenite & 0.031 & 0.031 \\
\hline
\end{tabular}

Boundaries: <none>

Figure 15. Phase analysis of the baseline processed materials which was austenitized, water quenched and cryo-quenched.
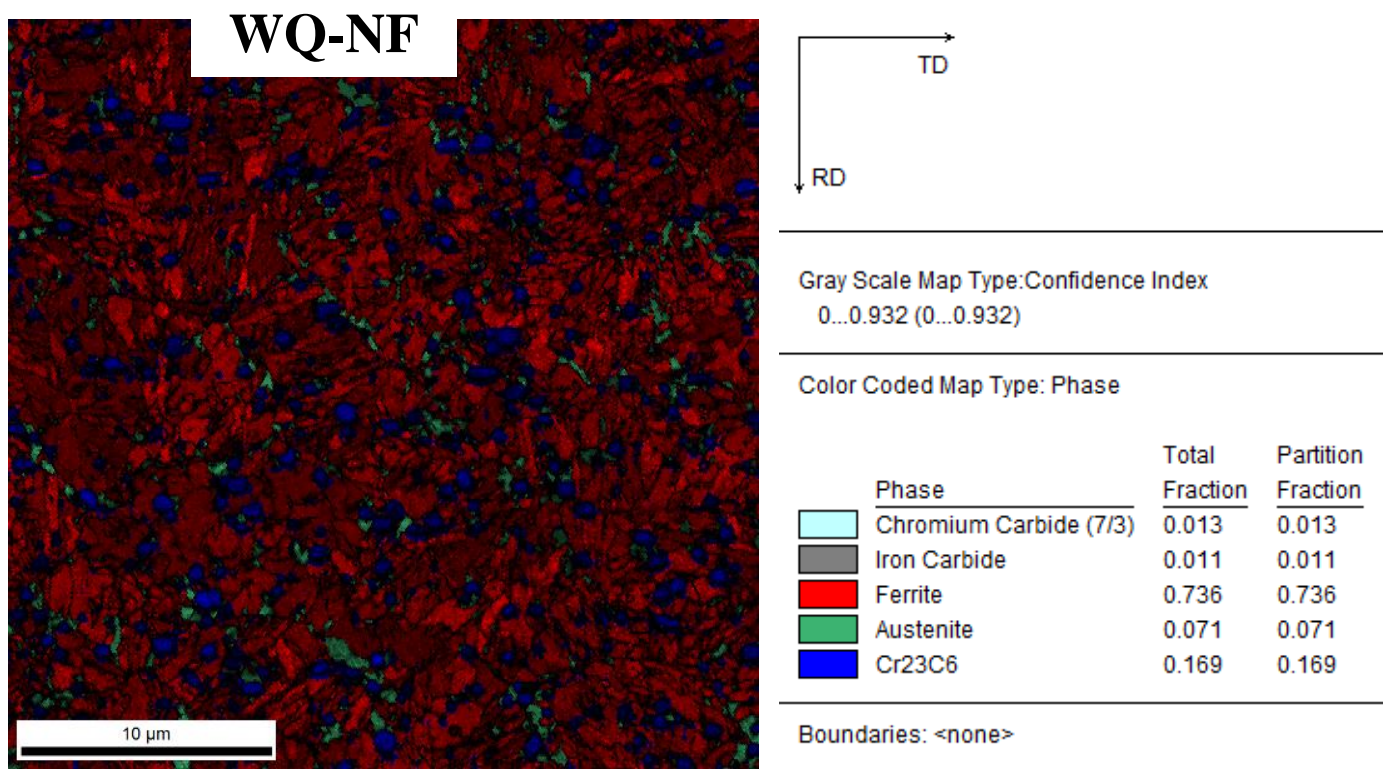

\begin{tabular}{|c|c|c|}
\hline \multicolumn{3}{|l|}{ Color Coded Map Type: Phase } \\
\hline & Total & Partition \\
\hline Phase & Fraction & Fraction \\
\hline$\overline{\text { Chromium Carbide (7/3) }}$ & 0.013 & 0.013 \\
\hline Iron Carbide & 0.011 & 0.011 \\
\hline Ferrite & 0.736 & 0.736 \\
\hline Austenite & 0.071 & 0.071 \\
\hline $\mathrm{Cr} 23 \mathrm{C} 6$ & 0.169 & 0.169 \\
\hline
\end{tabular}

Boundaries: <none>

Figure 16. Phase analysis of sample $B 5$ which was austenitized then water quenched. 

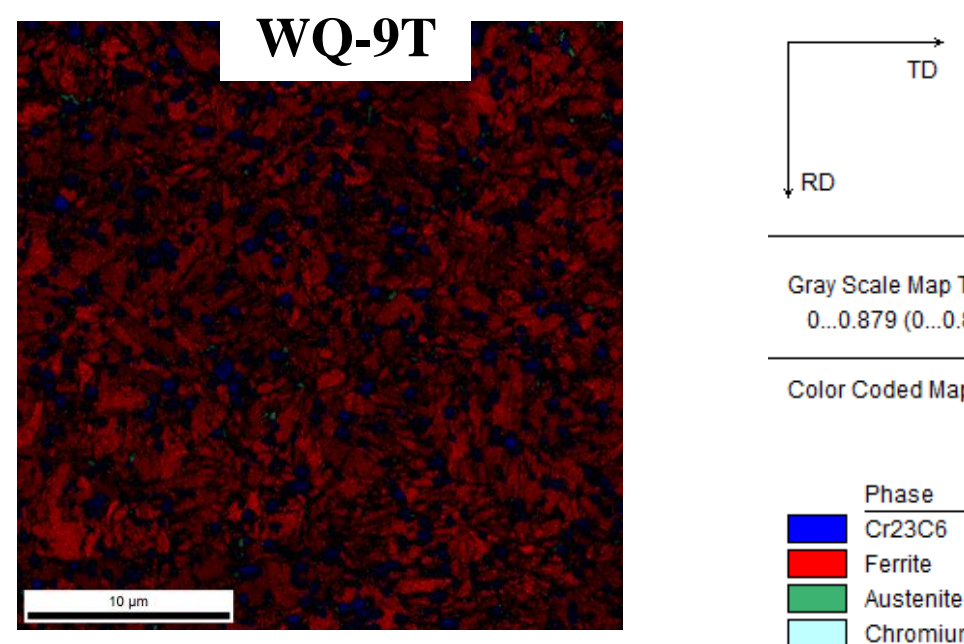

Gray Scale Map Type:Confidence Index
$0.0879(0,0.879)$

\begin{tabular}{|c|c|c|}
\hline \multicolumn{3}{|l|}{ Color Coded Map Type: Phase } \\
\hline & Total & Partition \\
\hline Phase & Fraction & Fraction \\
\hline $\mathrm{Cr} 23 \mathrm{C} 6$ & 0.154 & 0.154 \\
\hline Ferrite & 0.723 & 0.723 \\
\hline Austenite & 0.021 & 0.021 \\
\hline Chromium Carbide (7/3) & 0.062 & 0.062 \\
\hline Iron Carbide & 0.039 & 0.039 \\
\hline
\end{tabular}

Boundaries: <none>

Figure 17. Phase analysis of sample D3 which was austenitized, water quenched and passed through a 9 Tesla field.

Thus this project has successfully demonstrated that the ambient temperature magnetic field processing heat-treatment approach that does not require cryo-quenching results in a finer, harder, and more homogeneous microstructure than conventional processes today for this razor blade steel strip heat treating application. 


\section{RESULTS AND DISCUSSION: ITMP CONFIGURATIO}

The goal of this effort was to validate the durability of the world's first commercial prototype thermomagnetic processing system which is located at ORNL (Figure 18). The high magnetic field superconducting magnet system had already been integrated relatively seamlessly with the ATM sample handling system, also called the "scanner", but the real issue to be tested was whether a magnet quench would occur at production-rate insertion rates during actual experimentation while a large bulk sample was inserted into the bore of the high magnetic field system while at full field. This commercial prototype thermomagnetic processing system incorporated several novel design concepts for enhancing system durability, and so this endeavor was undertaken to validate and document the industrially robust design as capable of handling the demands on all of the system components to meet the high throughput requirements of an industrial environment.

The ORNL commercial prototype system is comprised of a 2000-pound force extraction/sample handling system involving sample rotation during heating and quenching that is integrated around a 9 tesla, $\sim 8$-inch diameter vertical bore superconducting magnet system with a $200 \mathrm{KW}(10-30 \mathrm{KHz})$ induction heating power supply and an in-bore 75 gpm quenching system. Figure 19 shows the internal induction heating system insert with integral quench ring built into the induction heating coil assembly prior to insertion in the bore of the superconducting magnet. Because of the high forces exerted on the high magnetic field superconducting solenoid coils during ferromagnetic sample insertion into the bore of the prototype system and the possibility of magnet quenching (loss of superconductivity due to temperature rise) due to inherent system component interactions, a series of critical experiments were conducted to prove commercial viability.

As discussed below, these tests showed that relatively large commercial components (several pound ferrous alloy samples [e.g., orbital drive or gear, Figure 20]) which would have a maximum extraction force up to 2000 pounds exerted on them) can be inserted and extracted rapidly at up to 10 inches per minute with multiple cycles (up to 45 were demonstrated) while under a 9 tesla magnetic field without causing any negative power changes in or quenching of the magnet solenoid. Tests under induction heating power were similarly conducted with no negative impact. These experiments provided critical data required by our technology commercialization partners AjaxTOCCO Magnethermic and American Magnetics Inc. to successfully design future next generation commercial prototype superconducting magnet systems incorporating induction heating systems for industrial applications at production rate speeds. 


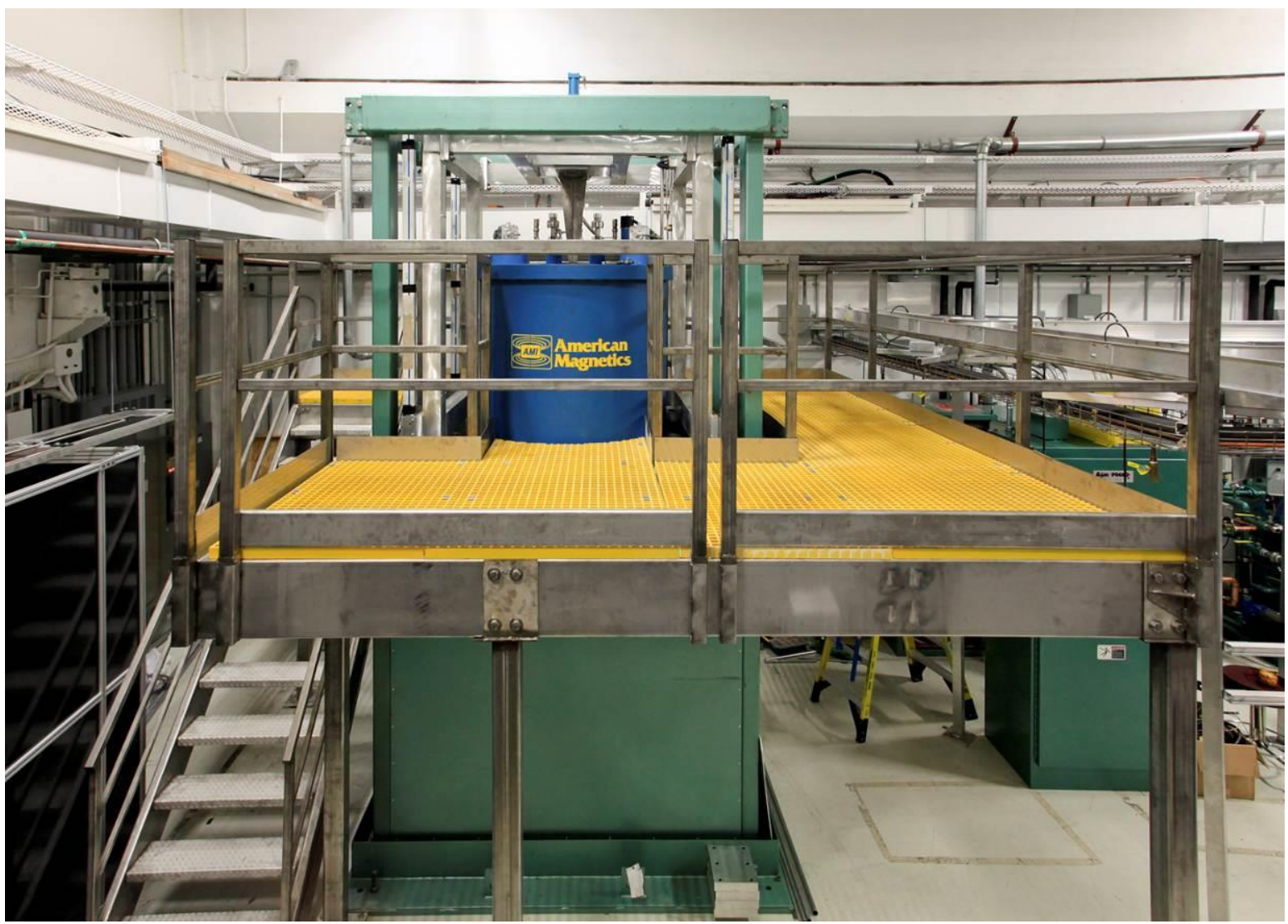

Figure 18. World's first commercial prototype H\&TMP/EMAT system with an $\sim 8$-inch diameter, vertical warm bore superconducting magnet system (with recondensing cryocoolers for zero cryogen replacement capability) and $200 \mathrm{KW}$ dual-frequency induction heating system with integral 75 gpm polymer-water quench.

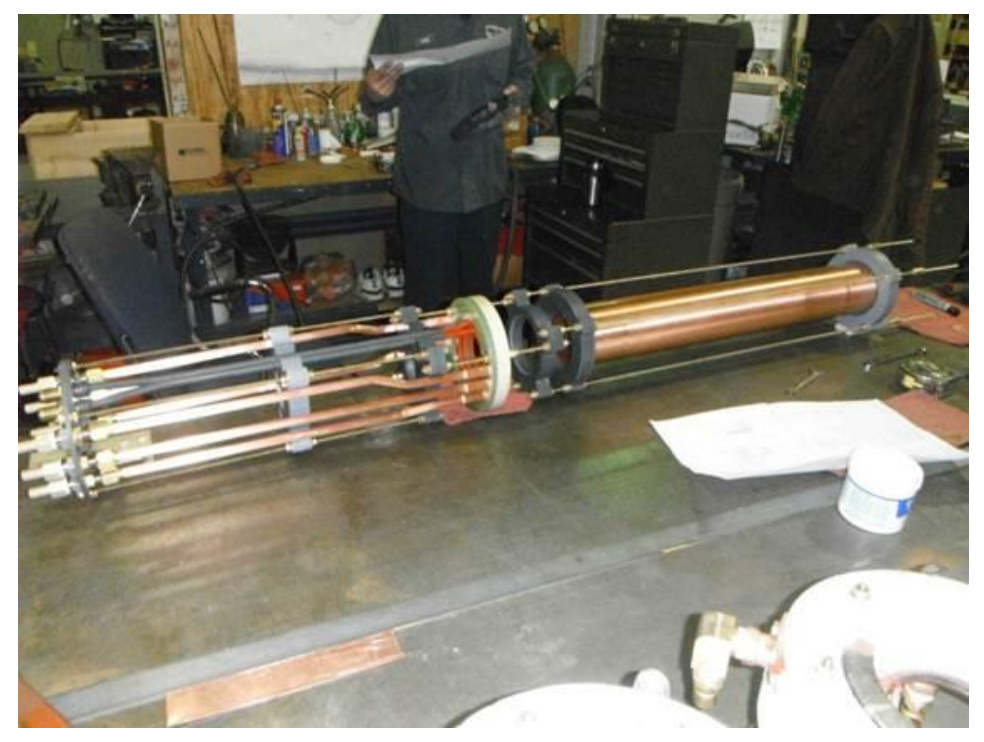

Figure 19. Internal induction heating insert with integral quench capability used for this investigation prior to installation in the vertical bore of the commercial prototype superconducting magnet system. 


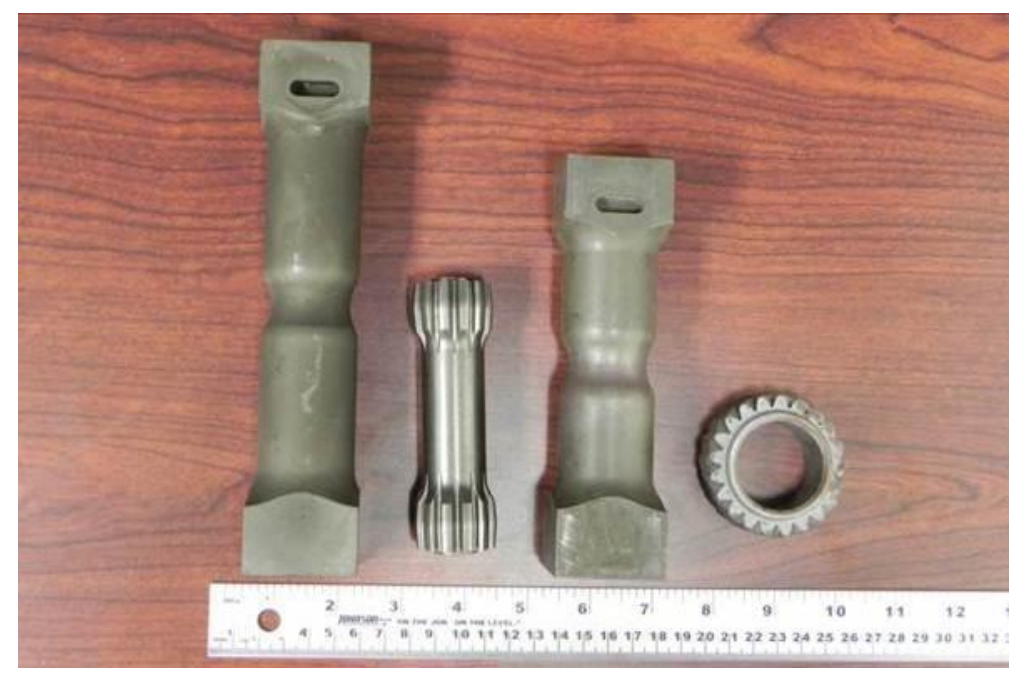

Figure 20. Typical ferrous alloy components (left to right: large torsion fatigue sample, orbital drive, small torsion fatigue sample, gear) that would need to be handled by the commercial prototype system at insertion rates up to 10 inches/s while under a 9 tesla magnet field.

To document response of the magnet system during these experiments and record all of the related processing parameters (such as field strength, induction heating power settings, etc.), the ORNL thermomagnetic processing group identified the need for key process data to be displayed and recorded during operation of the commercial prototype thermomagnetic processing system. The team used the National Instruments LabView product that was already in use by some of the equipment components and the virtual instrument programming expanded to provide this capability. This key process data resided in the various control and instrumentation systems. The induction power supply, quench, and vertical servo lift is controlled with a Rockwell ControlLogix programmable logic controller (PLC) system. The magnet system is controlled by an American Magnetics MN-430 Power Supply controller. An optical pyrometer temperature measurement capability was established with a Sekidenko system to monitor temperature to augment intrinsic Type $\mathrm{S}$ thermocouples spot-welded to test components as shown in Figure 21.

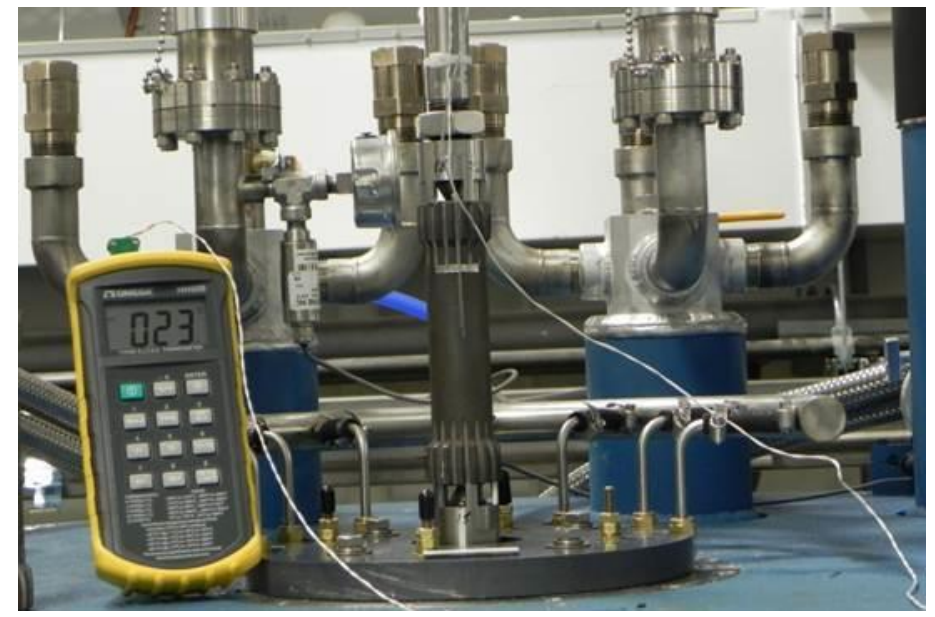

Figure 21. A typical ferrous alloy test component instrumented for temperature measurement with a Type $S$ intrinsic thermocouple spot-welded to the sample surface. Sample is shown at the top entrance of the superconducting magnet being held by the 2000-pound force sample handling system. Liquid helium recondensing cryocooler components (multiple vertical assemblies) are shown in the background. 
A local Ethernet Transmission Control Protocol/Internet Protocol (TCP/IP) network was configured consisting of the Rockwell ControlLogix PLC, American Magnetics MN-430 Power Supply Controller, Sekidenko Optical Pyrometer, and a laptop computer. The laptop computer operated the National Instruments LabView control and data acquisition program. A LabView virtual instrument was developed using libraries for industrial Ethernet, American Magnetics, and reference user case examples from National Instruments. The virtual instrument queried each device for specific data, displayed the data, and recorded the data. The combination of acquiring PLC process data (servo vertical lift position, servo torque, induction power supply output power, and quench parameters) with magnetic data (voltage, current, and field strength) and other critical experiment data such as temperature measurement was a key capability established by the group to accomplish this critical series of experiments to substantiate the robustness of the system for implementation in an industrial environment. The data acquisition rate (10 per second) was chosen to parallel the AMI power supply controller rate to eliminate any potential compatibility problems that could result in a partial magnet quench not related to sample insertion speed or magnetic field strength.

After the large sample induction heating and quenching insert was received from ATM and installed in the bore of the magnet and integrated into the power supply of the ATM $220 \mathrm{KW}$ system and scanner assembly, a carburized 8620 gear (shown in figure 20) was used for the initial prove-in stage of this commercialization project. A series of insertion and actual TMP experiments with sample rotation (for boundary condition uniformity for homogeneous mechanical property development in the parts) during heating and quenching were conducted that identified several operational issues resulting in specimen rotation stopping in the middle of a TMP experiment. Although initially these were thought to be due to the high magnetic field, careful analyses and controlled experiments under zero magnetic field conditions determined these to be scanner and specimen heating/quenching insert design issues. Therefore, the commercial prototype TMP system design was proving to be eddy current and $\mathbf{J} \mathrm{x}$ B force (non-contact acoustic transduction force) problem resistant. The positive aspect of these initial experiments and their conclusion was that the TMP system was not having issues associated with high magnetic fields that might raise barriers to commercialization.

Subsequently sample mass (equivalent to half the orbital drive mass shown in Figure 20 for initial testing) insertion rate experiments without sample rotation or heating were initially conducted from 0 to 8.5 Tesla at insertion rates from 0.5 inch to 6 inches per second without any negative impact on the superconducting magnet performance. These experiments were stopped once some sample insertion spindle and bearing wear/spindle seizing issues were determined while we worked with ATM engineering to alleviate these issues. This involved running a series of carefully designed experiments and videotaping different components during the initial testing until the rotation seizing occurred.

ATM engineers defined the following steps needed to be accomplished to eliminate the spindle seizing (rotation stopping issue) problem: 1) remake the upper and lower bushing on the lower spindle from a stronger material so as to have less wear/galling; 2) replace the roller bearing thrust washer with a bronze bearing of higher strength material. Provide backup steel and ceramic bearings as backup; 3 ) provide a bearing washer to provide a flat surface under the locking collar to distribute load more evenly; and 4) cut slots in the lower guide sleeve to release quench and any component oxide scale that may develop. It is critical to note that the need for these modifications was not due to any high magnetic field effects or possible magnet quench issue which was reassuring for the future TMP technology commercialization viability.

After several of the system modifications described above were implemented based on the feedback and replacement parts supplied by ATM, sample (equivalent to half the HP30 orbital drive mass for initial testing) insertion rate experiments without sample rotation or heating were conducted at 9 Tesla 
at insertion rates of 10 inches per second without any negative impact on the superconducting magnet performance. After a total of 45 repetitive insertions/extractions the current in the magnet (in persistent mode) had not changed, which means the new superconducting magnet design and the sample insert components designed to mitigate against any magnet quenching (due to the EMAT) were very effective. Therefore, extraction rate commissioning was successfully completed at extraction rate speeds from 0 to $10 " / s e c$. Also noted is the fact that the induction insert did not show any indications of vertical motion during extractions at speeds up to and including 10"/sec which further attested to the robustness of this current commercial prototype ITMP system design. One potential issue identified was that tests run at the highest insertion rates and rapid repeat cycles (up to the 45 total) resulted in the gear box attached to the motor to get hot. This issue was conveyed to ATM design staff for future commercial system design considerations.

Insertion rate tests were attempted at $12 \% / \mathrm{sec}$ but the scanner interlock system kicked in and turned off the system automatically. After review with ATM design personnel and their fabrication specifications, this thermodynamic processing system design configuration for insertion rate was built for just slightly higher than $10 \% / \mathrm{sec}$ and was not designed to go to $12 \% / \mathrm{sec}$. This is just a matter of changing gear-box reduction ratio components in any future system designs or the current ORNL system. Therefore, demonstration of this prototype equipment commercial viability goal for this project was accomplished since the scanner assembly has covered its original design space for insertion speed rates without causing any magnet quenching problems.

At the conclusion of this project, ORNL staff provided the following inputs/guidance to ATM regarding future designs of commercial thermomagnetic processing systems to make the systems robust, production-rate capable, industrial environment/application viable, and facilitates easier/safer maintenance operations:

- Sample rotation subsystem of scanner was in constant need of repair. Constantly having to making on-the-fly repairs is not amenable for an industrial environment.

- Quench flow sensor was inaccurate and needs to be upgraded to enable controllable, variable quench-rate capability for different component and alloy family applications in a commercial setting.

- Power lead connections show signs of weeping due to excessive amount of rework required up to this point to handle multiple component types/inserts (in this project and two other major projects) and therefore a more robust connection system would be beneficial.

- Cannot service bottom spindle bearing due to strengthening/stiffening modifications of scanner framework. Alternate scanner design for enhanced frame stiffness for future systems is mandated.

- Top spindle removal is potentially hazardous, cumbersome, and has the potential to damage the insert/ components. Future systems need to be more operator friendly and allow easier and safer access for insert change-out and maintenance.

- Rotation belts have become loose and vibrate during rotation. This is assumed to be from the many instances of rotational binding which is a prototype (serial number 1) system design issue that must be addressed for future commercial systems.

- Desired induction heating programmed files do not consistently load/save correctly. Heating programs will randomly not save or drop segments during the load/save function.

This project has not identified any high magnetic field or magnetic quench related equipment issues for ORNL's commercial prototype ITMP system that might hint at any technology commercialization limitations for a broad range of typical ferrous alloy (most severe case) component applications. The scanner/induction heating system issues defined above can be readily mitigated through viable redesign considerations. 


\section{CONCLUSIONS}

A laboratory-scale continuous razor blade processing line incorporating ORNL's ambient temperature high magnetic field technology for increased energy efficiency and material performance enhancement was successfully demonstrated during the project. Magnetic processing resulted in improved process energy efficiency, reduced microstructural variability in the final product, and higher hardness for better performance than currently employed cryogenic commercial processing. Therefore, from both a technical and cost benefit perspective, high magnetic field processing incorporated into a razor strip production line was shown to be a technically-feasible, commercially-viable approach to making a superior razor blade product. In this razor blade application, magnetic processing was shown to reduce the variation in materials with microstructures differing by over $5 \% \mathrm{wt} \%$ retained austenite down to less than a percent. Thus the project successfully demonstrated that the ambient temperature magnetic field processing heat-treatment approach that does not require cryo-quenching results in a finer, harder, and more homogeneous microstructure than conventional processes used today for this razor blade steel strip heat treating application.

The ITMP prototype system is the first of its kind and incorporates several novel design concepts for system durability. This commercial prototype is comprised of a 2000-pound force extraction/sample handling system involving sample rotation during heating and quenching that is integrated around a 9 tesla, 8-inch diameter vertical bore superconducting magnet system with a $200 \mathrm{KW}(10-30 \mathrm{KHz})$ induction heating power supply and an in-bore 75 gpm quenching system. Because of the high forces exerted on the high magnetic field superconducting solenoid coils during ferromagnetic sample insertion into the bore of the prototype system and the possibility of magnet quenching (loss of superconductivity due to temperature rise) due to inherent system component interactions, a series of critical experiments were conducted to prove commercial viability in the project. These tests showed that relatively large commercial components (several pound ferrous alloy samples [e.g., orbital drive or gear] which would have a maximum extraction force up to 2000 pounds exerted on them) can be inserted and extracted rapidly at up to 10 inches per second with multiple cycles (up to 45 were demonstrated) while under a 9 tesla magnetic field without causing any negative power changes or quenching of the magnet solenoid. These experiments provided critical data required by our technology commercialization partners AjaxTOCCO Magnethermic (ATM) and American Magnetics Inc. (AMI) to successfully design future next generation commercial prototype superconducting magnet systems incorporating induction heating systems for industrial applications at production rate speeds. 


\section{COMMERCIALIZATION}

ORNL has not identified any high magnetic field or magnetic quench related equipment limitation issues for ORNL's commercial prototype system that might hint at any technology commercialization limitations for a broad range of typical ferrous alloy component applications. Scanner system robustness and maintenance safety issues, plus the need for enhanced ease and speed of induction heating insert replacement, have been identified through this project and discussed with the potential technology commercializers for remediation in future designs. Our commercial partners have received inquiries from potential customers for systems modeled on the ORNL commercial prototype and for a superconducting magnet system with a 24-inch diameter warm bore 1-T system (Figures 22 and 23).

\section{1-T Recondensing Superconducting Magnet Design (Integral Induction Heating System Not Shown) with a 24-inch Diameter Warm Bore for Continuous Processing of Bars/Rails}

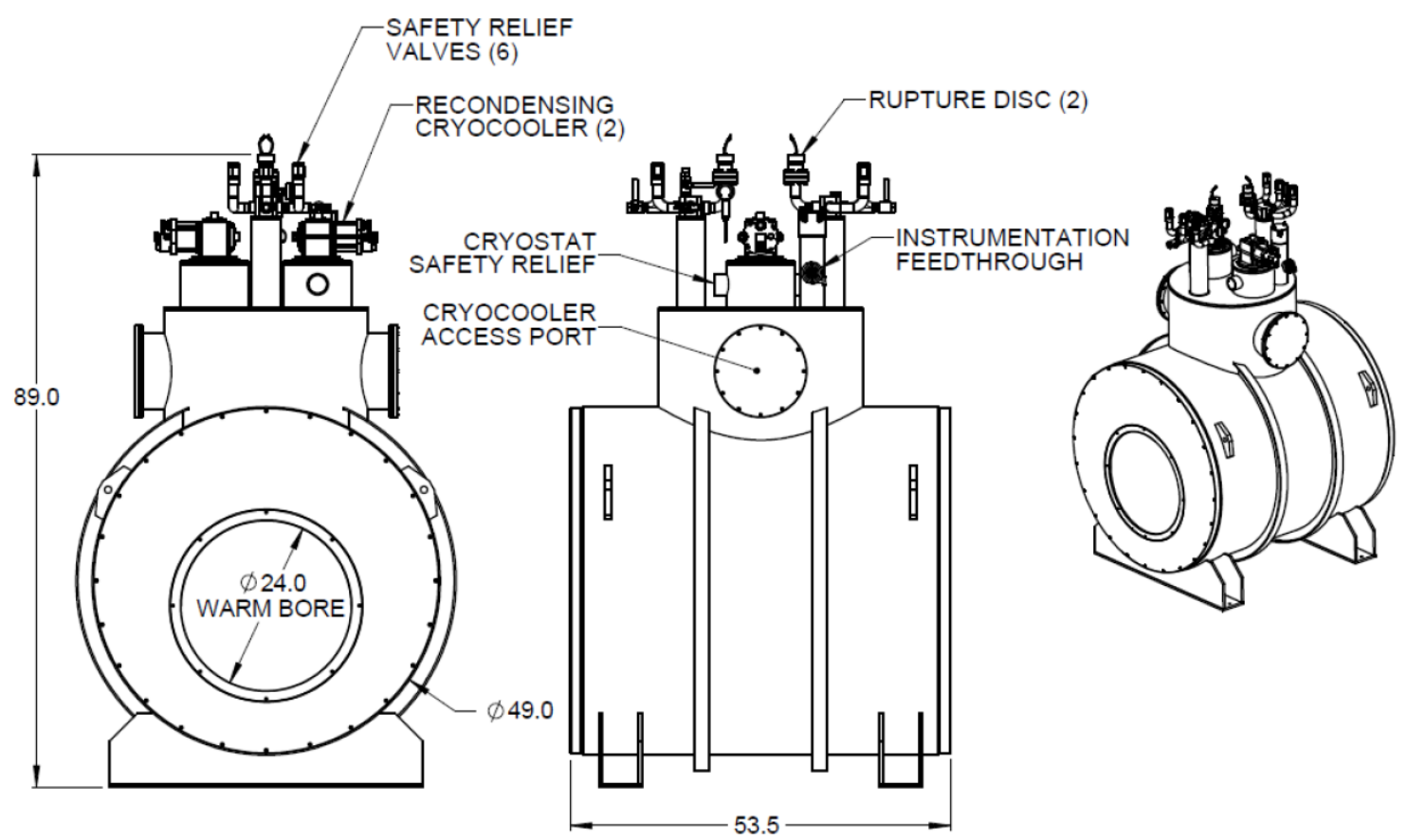

Figure 22. Schematic of a 1-T recondensing magnet design with a 24-inch diameter warm bore that would be viable for continuous processing of ferrous alloy bar and rod industrial applications. 


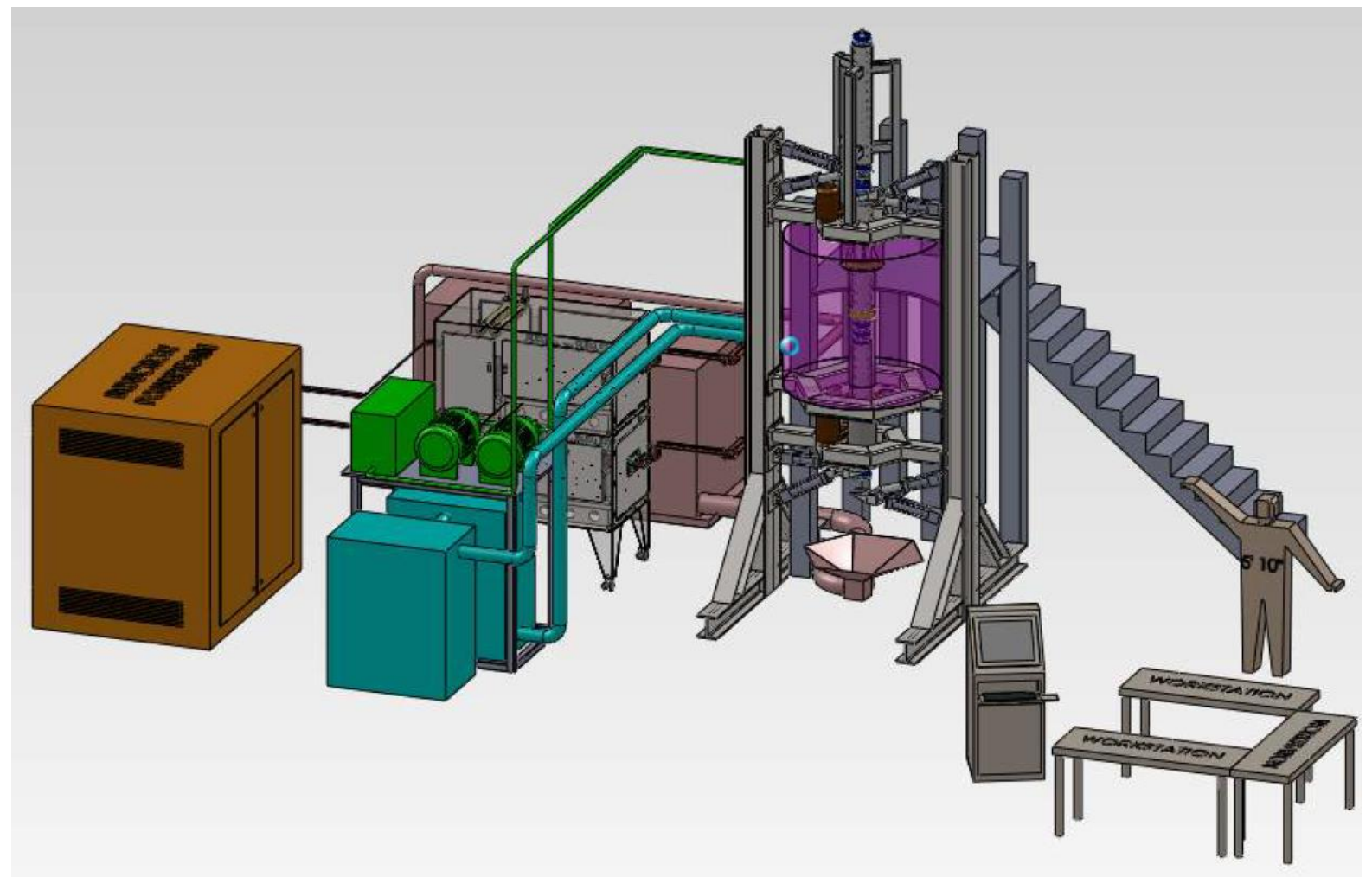

Figure 23. Schematic production-rate capable prototype commercial system with all of the system enhancements identified in this project that would have been the first implementation of the H\&TMP technology.

One potential barrier that may be perceived by an industrial end-user of the H\&TMP technology is the apparent high forces exerted on components during insertion into and extraction from the bore of a high magnetic field superconducting magnet system. This issue was addressed for a specific subset of samples (meaning mass size) shown in Figure 20. Figure 24 shows how magnetic field strength can impact the effective force on a ferromagnetic sample such as the torsional fatigue sample. 


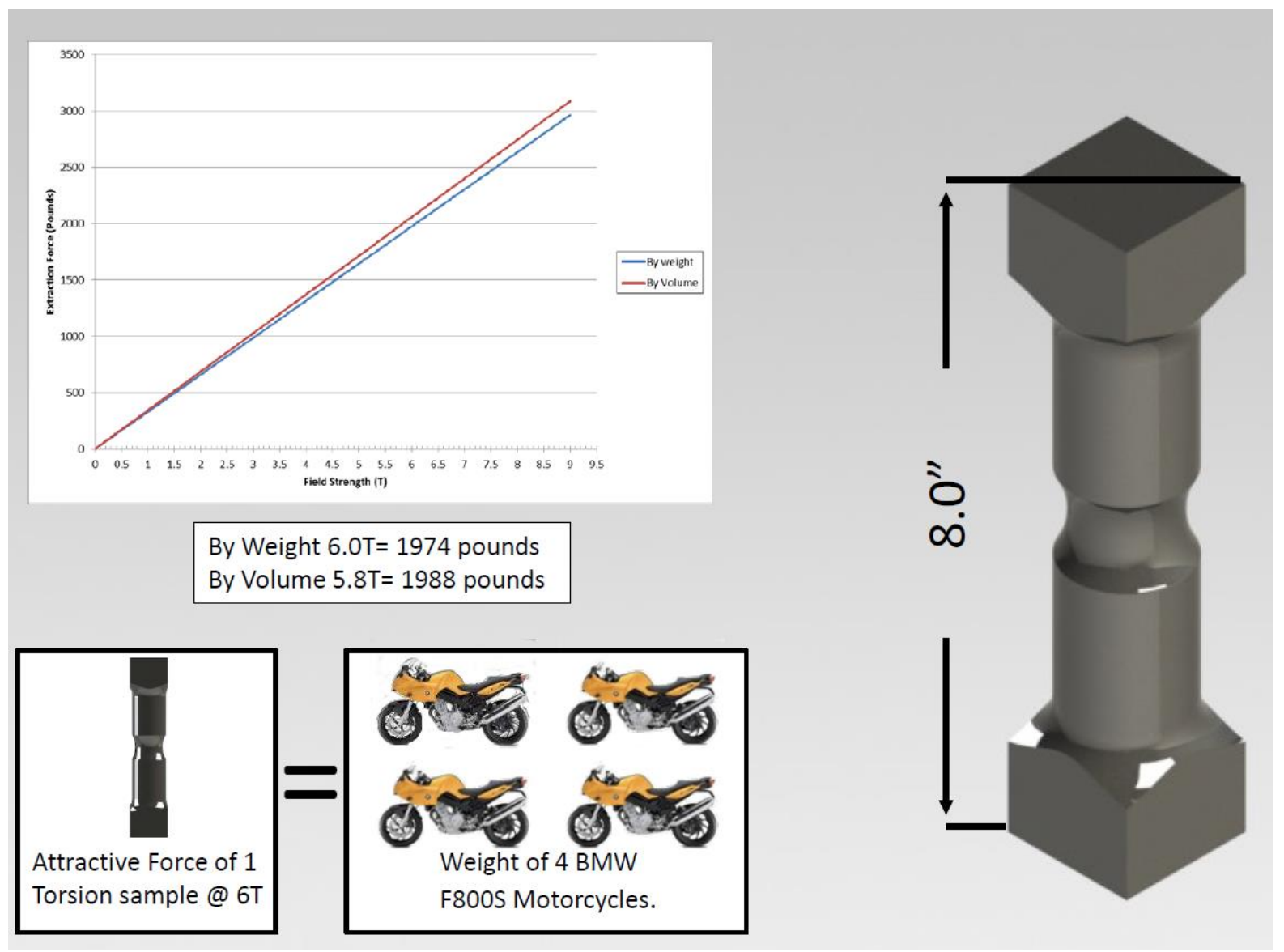

Figure 24. An illustration of the high forces as a function of field strength that may be exerted on a ferromagnetic sample while going through the magnetic field gradient of a superconducting magnet. An 8-inch long torsional fatigue sample would have the apparent mass of the 4 sport motorcycles depicted in this graphic.

ORNL researchers have conceived a very innovative solution to this apparent problem by realizing that the magnetic field within the bore of the magnet is symmetric about the centerline and so there exists two magnetic field gradient zones that pull (with equal strength but opposite direction) ferromagnetic samples towards the uniform field region of the superconducting magnet center. Therefore, if a continuous bar is within the bore of the magnet, the attractive forces would balance to zero and the rod would effortlessly be fed in one end of the magnet and out the other. Figure 25 demonstrates that if one ferromagnetic sample was fed through the magnet from one end to the other it would go through two regions where it would experience forces on the order of 1900 pounds. However, if multiple samples of the same mass are configured such that they are precisely spaced on an insertion arm that as you increase the number of samples and decrease their spacing the forces will eventually approach the zero pound case of a continuous rod. Therefore, components such as gears, drives, or bearing races can readily be continuously fed into a production H\&TMP system while effectively experiencing very low forces making the high magnetic field environment rather benign from a force handling perspective and mitigate/negate the need for a high load capacity sample handling system. 


\section{Magnetic Attraction Forces During Insertion/Extraction Can be Easily Mitigated through Intelligent Design}
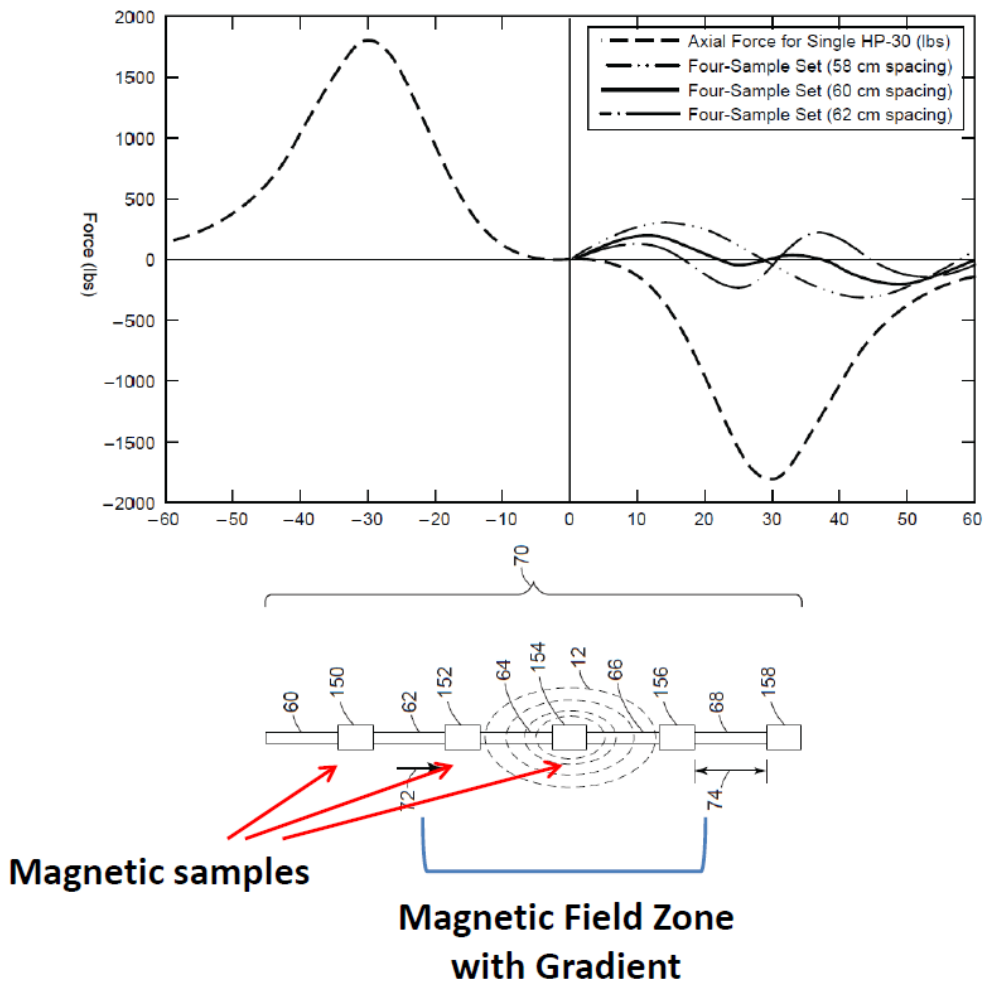

Figure 25. Production rate, commercial H\&TMP systems with continuous feed sample insertion systems can be intelligently designed such that the effective handling force on the samples approaches very low values. 


\section{BIBLIOGRAPHY}

1. "Magnetic Field Processing - A Heat Free Heat Treating Method", Gerard M. Ludtka, et al, ORNL Tech. memo, ORNL/TM-2012/78, August 8, 2012, www.osti.gov/servlets/purl/1049805/

2. "Magnetic Processing of Structural Components for Transportation Vehicles", Gail M. Ludtka, Gerard M. Ludtka, Sean Fleming, and Joaquin del Prado Villasana, Final CRADA Report for ORNL CRADA No. NFE -09-02418, September 30, 2011.

3. "An Attractive Materials Process: Exploring High Magnetic Field Processing for Developing Customized Microstructures with Enhanced Performance", Mackiewicz-Ludtka, et al., 2007, Symposium Proceedings of the 2007 ASM Heat Treat Society Conference \& Exposition, Detroit, MI, September 17-19-2007.

4. "Time-Resolved Analyses of Microstructure in Advanced Materials under High Magnetic Fields at Elevated Temperature Using Neutrons", Ludtka, et al, (invited paper) in Materials Processing Under the Influence of External Fields, Q. Han, G. Ludtka, and Q. Zhai, editors, Symposium Proceedings from the TMS 2007 Annual Meeting, Orlando, FL, February 25-March 1, 2007, TMS Publishers, Warrendale, PA, 2007.

5. "Isothermal Phase Transformation Cycling in Steel by Application of a High Magnetic Field", Ludtka, et al, in Materials Processing Under the Influence of External Fields, Q. Han, G. Ludtka, and Q. Zhai, editors, Symposium Proceedings from the TMS 2007 Annual Meeting, Orlando, FL, February 25-March 1, 2007, TMS Publishers, Warrendale, PA, 2007.

6. "Retained Austenite in SAE 52100 Steel Post Magnetic Processing and Heat Treatment", Ludtka, et al, in Materials Processing Under the Influence of External Fields, Han, Ludtka, and Zhai, editors, Symposium Proceedings from the TMS 2007 Annual Meeting, Orlando, FL, February 25-March 1, 2007, TMS Publishers, Warrendale, PA, 2007.

7. "Exploring Ultrahigh Magnetic Field Processing of Materials for Developing Customized Microstructures and Enhanced Performance", Ludtka, et al, in Materials Processing in Magnetic Fields (Eds. Schneider-Muntau, H. J. and Wada, H.), World Scientific Publishing, New Jersey, pp 55-65 (2005).

8. "Texture Evolution in Fe-1\%Si As A Function of High Magnetic Field", T. A. Bennett, R. A. Jaramillo, D. E. Laughlin, J. B. Wilgen, R. Kisner, G. Mackiewicz-Ludtka, G. M. Ludtka, P. N. Kalu, and A. D. Rollett, Solid State Phenomena, (105), 2005, 151-156.

9. "In-situ Evidence of Enhanced Phase Transformation Kinetics Due to a High Magnetic Field in a Medium Carbon Steel", Ludtka, et al, Scripta Materialia, (51), 2004, 171-174.

10. "The Effect of High Magnetic Field Annealing on Enhanced Phase Stability in 85Fe-15Ni", Ludtka, et al, Journal of Applied Physics, (95) No. 11, June 2004, 6580-6582.

11. "Effect of 30 Tesla Magnetic Field on Phase Transformations in a Bainitic High-Strength Steel", R. A. Jaramillo, S. S. Babu, G. M. Ludtka, R. A. Kisner, J. B. Wilgen, G. Mackiewicz-Ludtka, D. M. Nicholson, S. M. Kelly, M. Murugananth, and H. K. D. H. Bhadeshia, Scripta Materialia, (52), 2005, 461-466.

12. "Investigation of Austenite Decomposition in High-Carbon High Strength Fe-C-Si-Mn Steel under 30 Tesla Magnetic Field", Jaramillo, R.A., Babu, S., Miller, M.K., Ludtka, G.M., MackiewiczLudtka, G. Kisner, R.A., Wilgen, J.B. and Bhadeshia, H.K.D.H, Proceedings of Int'l Conf. on Solid-Solid Phase Transformations in Inorganic Materials 2005, May 29-June 3, 2005, Phoenix, Arizona.

13. "Investigation of Phase Transformation Kinetics and Microstructural Evolution in 1045 and 52100 Steel under Large Magnetic Fields", Jaramillo, R.A., Ludtka, G.M., Kisner, R.A., Nicholson, D.M., Wilgen, J.B., Mackiewicz-Ludtka, G., Bembridge, N. and Kalu, P.N., Proceedings of Int'1 
Conf. on Solid-Solid Phase Transformations in Inorganic Materials 2005, May 29-June 3, 2005, Phoenix, Arizona.

14. "Exploring Ultrahigh Magnetic Field Processing of Materials for Developing Customized Microstructures and Enhanced Performance", Ludtka, G. M., Jaramillo, R. A., Kisner, R. A., Mackiewicz-Ludtka, G., Wilgen, J. B., ORNL Tech. memo, ORNL/TM-2005/79, March 2005, www1.eere.energy.gov/manufacturing/industries_technologies/imf/pdfs/1792magneticprocessingf inal.pdf

15. "Annual Report", American Iron and Steel Institute, 2006, Washington, DC, http://www.steel.org/

16. "Characterization of Retained Austenite and Carbides in Stainless Steel by Combined EBSD, EDS, and XRD”. Parish, C.; Watkins, T.; Rios, O.; Mackiewicz-Ludtka, G.; Ludtka, G.; Cavin, O. Publication: Microscopy and Microanalysis, vol. 17, issue S2, pp. 410-411.

17. "Microstructural Modification of a Cast Iron by Magnetic Field Processing", E.A. Kenik, G. Mackiewicz-Ludtka , G.M. Ludtka, J.B. Wilgen and R.A. Kisner, Conference Proceedings Microscopy and Microanalysis 2010, Cambridge University Press.

18. "Electron Microscopy Study of Hypo-Stoichiometric Fe-Pd Nanocomposites Resulting from Combined Reaction Thermomechanical Processing", E. D. Cantando, G. M. Ludtka G. Mackiewicz-Ludtka, and W. A. Soffa, 2011, Solid State Phenomenon, v. 172-174, p.356-361. 
Appendix A

RAZOR BLADE AMBIENT TEMPERATURE HIGH MAGNETIC FIELD PROCESSING SYSTEM DETAILS 



\section{Appendix A. RAZOR BLADE AMBIENT TEMPERATURE HIGH MAGNETIC FIELD PROCESSING SYSTEM DETAILS}

The following baseline process equipment was setup in Building 5500 at ORNL to continue development of the baseline magnetic processing in conjunction with a new 9-Tesla superconducting (SC) magnet:

1) Supply reel

2) Furnace

3) Chill block

4) Tension monitor

5) Take-up reel

This list is in order of processing, with the horizontal superconducting magnet positioned between the chill block and the tension monitor. A support structure was designed [Figures A1-A3] and fabricated for this equipment to ensure repeatable alignment with the magnet and easy longitudinal positioning along the central axis. An additional feature is the ability to quickly remove the supporting structure and processing components as a unit and roll it out of the aisle to facilitate moving large components through the high-bay area.

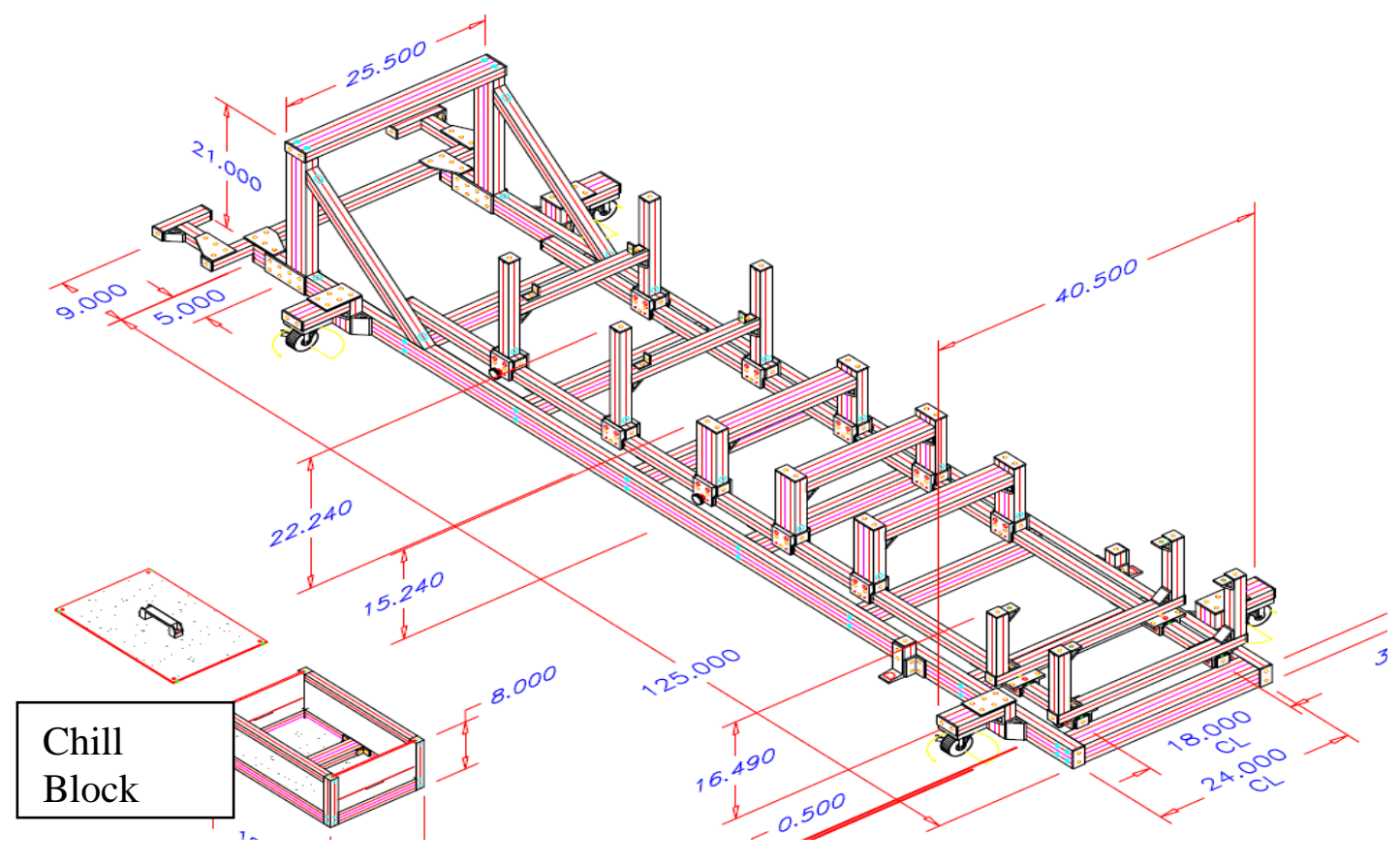

Figure A1. Support Frame Structure. 


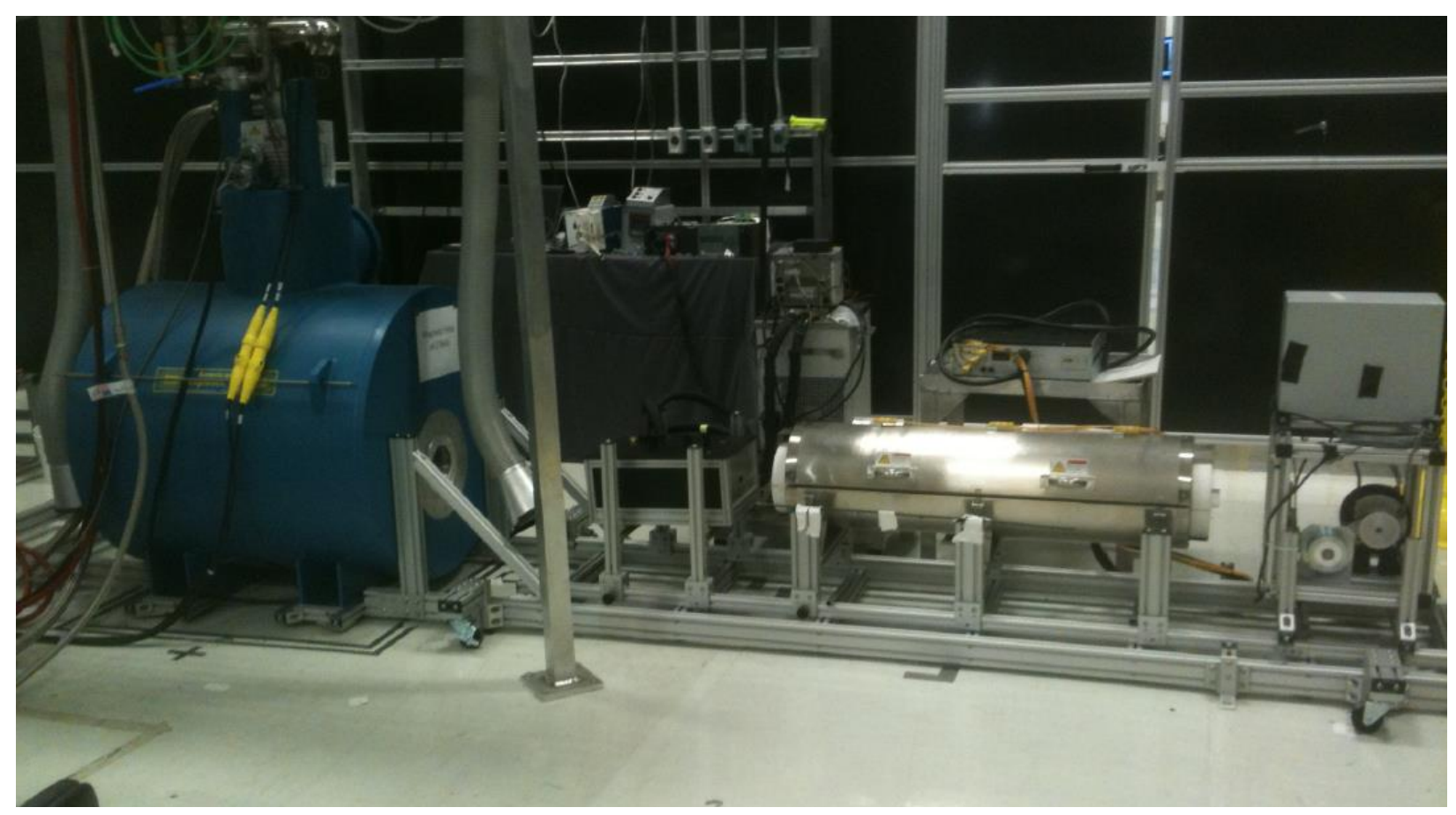

Figure A2. Support Frame with Process Equipment.

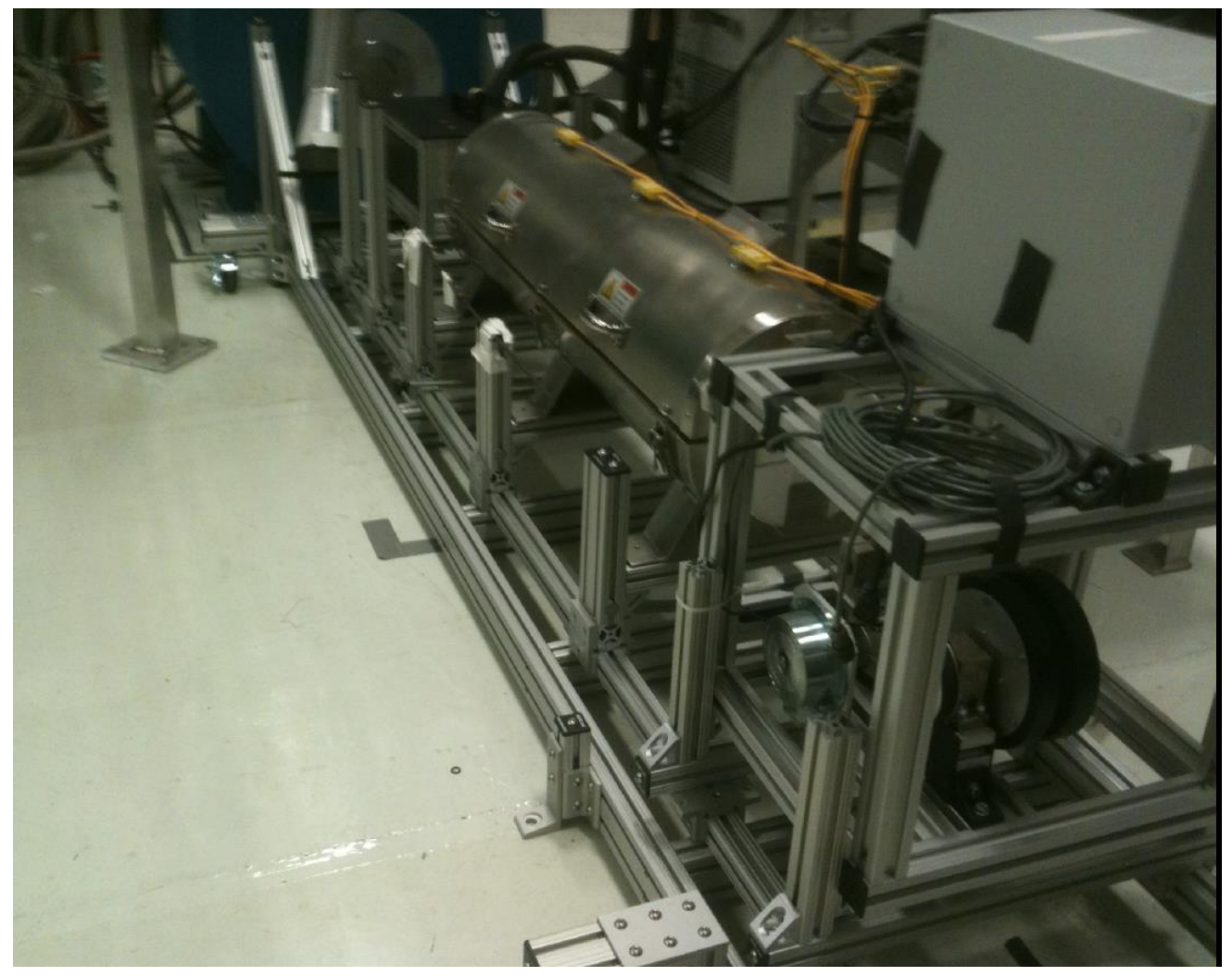

Figure A3. Process Equipment View.

A new housing for the chill block was also designed and fabricated (Figures A4-A7). The purpose of 
the new housing for the chill block is to:

1) Provide adjustable support

2) Provide a nitrogen atmosphere around the block to minimize condensation

3) Provide a mount for an experimental optical temperature sensor

4) Thermally isolate the block for better efficiency

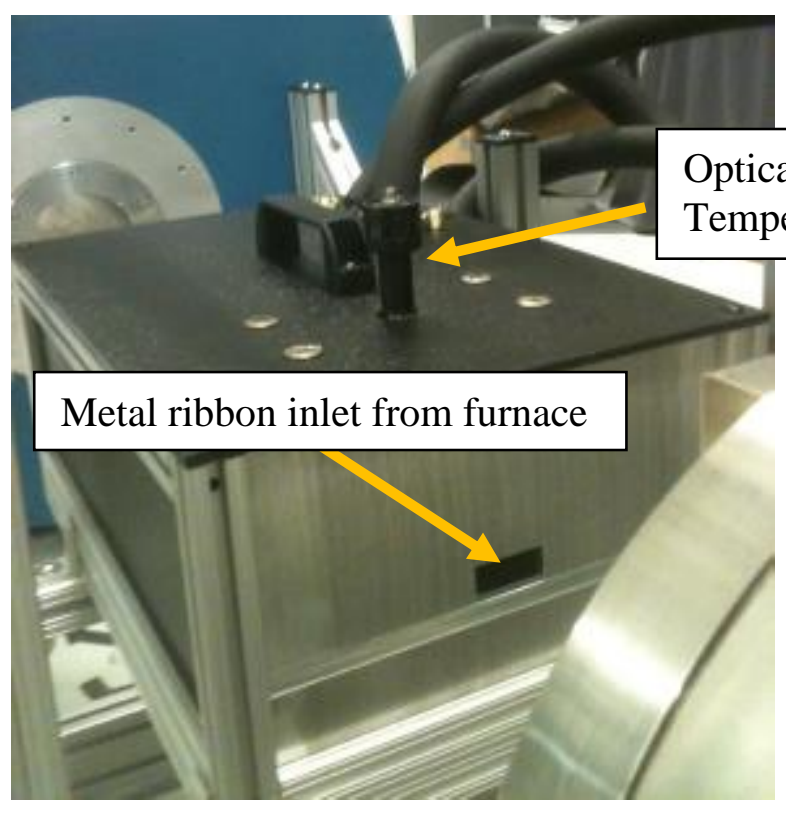

Figure-A4.

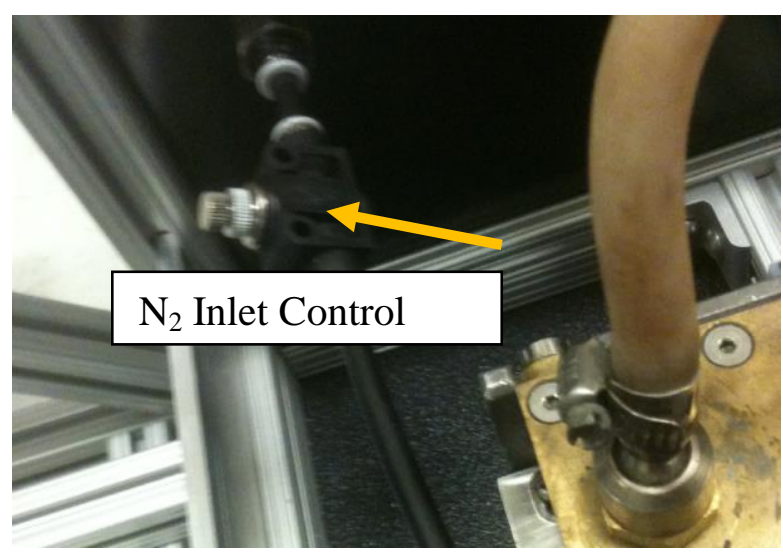

Figure-A6.

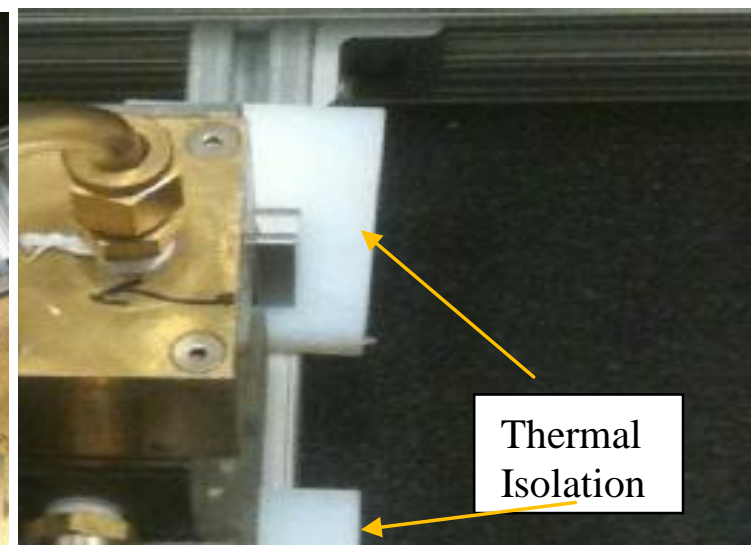

Figure-A7.

To lengthen the amount of processed material per run, the take-up and supply reels were modified to accommodate up to 500 feet of $0.1 \mathrm{~mm}$ metal ribbon. The existing side plates were modified to support Delrin spacers (Figures A8 - A10). 


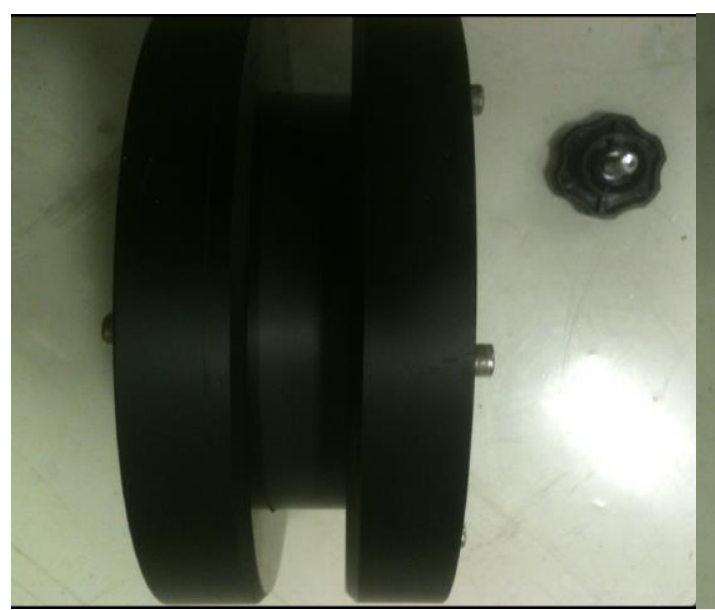

Figure-A8.

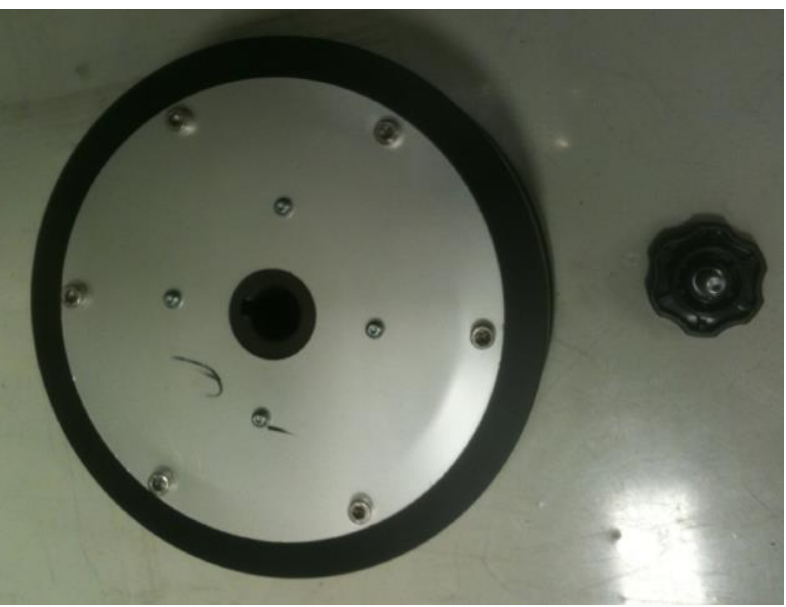

Figure-A9.

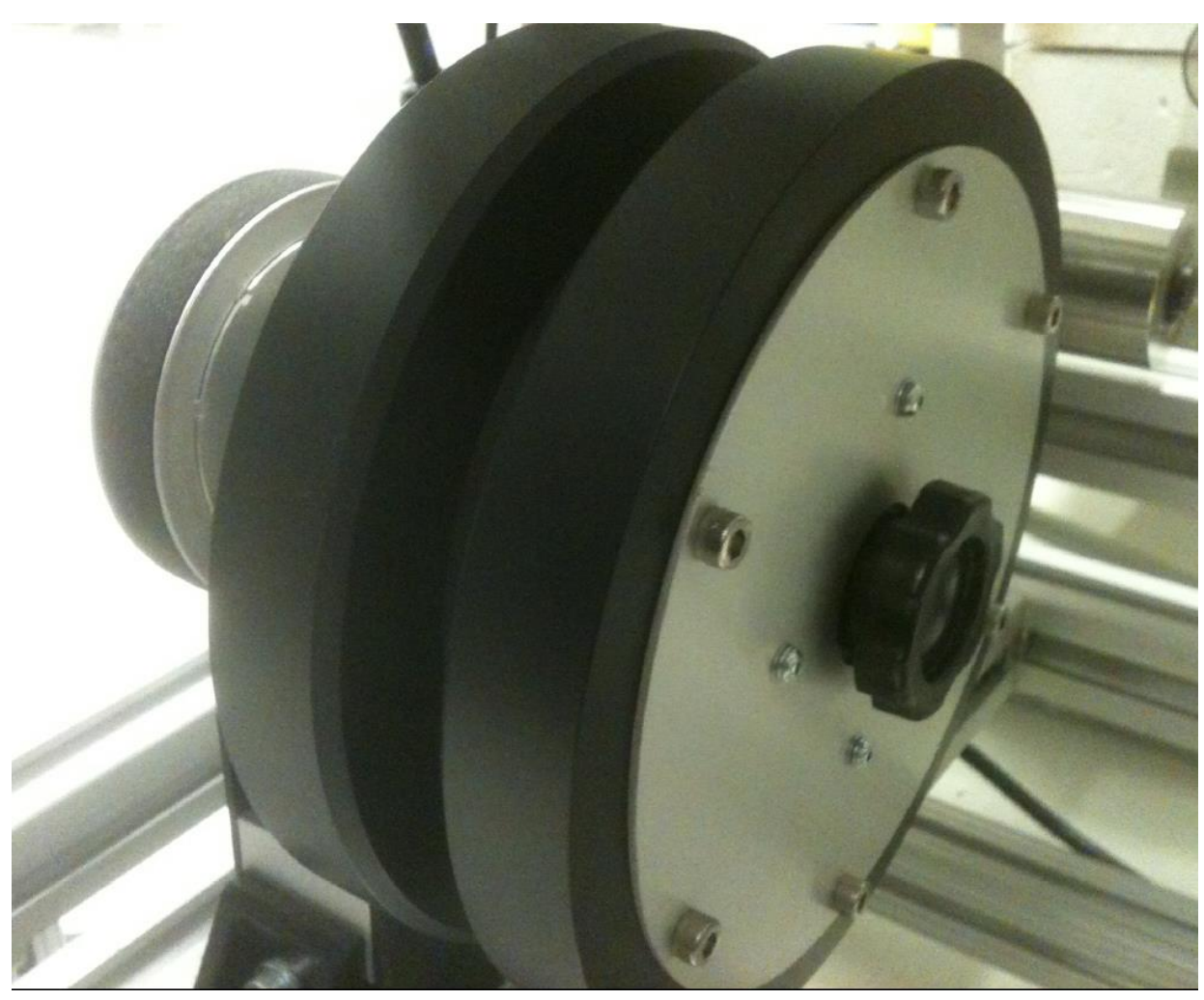

Figure-A10 

